\title{
Multi-Response Optimization and Prediction of Tribological behaviours of Filled Polytetrafluoroethylene Composites Using Taguchi- Deng and Evolutionary Harris Hawk's Optimization Methodologies
}

Musa Alhaji lbrahim ( $\nabla$ musaibrahim@kustwudil.edu.ng )

Kano University of Science and Technology Wudil

Hüseyin Çamur

Near East University

Mahmut A. Savaş

Near East University

Abba S.I.

Kano University of Science and Technology Wudil

Research Article

Keywords:

Posted Date: February 24th, 2022

DOI: https://doi.org/10.21203/rs.3.rs-1393204/v1

License: (c) (i) This work is licensed under a Creative Commons Attribution 4.0 International License.

Read Full License 


\title{
Multi-Response Optimization and Prediction of Tribological behaviours of Filled Polytetrafluoroethylene Composites Using Taguchi-Deng and Evolutionary Harris Hawk's Optimization Methodologies
}

\author{
Musa Alhaji Ibrahim ${ }^{1,2, ~ *}$, Hüseyin Çamur ${ }^{2}$, Mahmut A. Savaş ${ }^{2}$, S.I. Abba ${ }^{4}$ \\ ${ }^{1}$ Kano University of Science and Technology Wudil, Kano, Mechanical Engineering Department, postcode, \\ Nigeria \\ ${ }^{2}$ Near East University, Mechanical Engineering Department, Nicosia, postcode, Cyprus \\ ${ }^{3}$ Kano University of Science and Technology Wudil, Kano, Physical Planning and Development, postcode, \\ Nigeria \\ ${ }^{4}$ Interdisciplinary Research Center for Membrane and Water Security, King Fahd University of Petroleum and \\ Minerals, Dhahran 31261, Saudi Arabia; sani.abba@kfupm.edu.sa \\ *musaibrahim@kustwudil.edu.ng
}

\begin{abstract}
Filled polymer composites are widely used for automobile, structural and aerospace components owing to their exceptional combination of high specific stiffness and strength. This study presents Taguchi-Deng optimization of tribological parameters such as load, grit size, distance and speed as well as prediction of tribological behaviours of carbon-filled and bronze-filled polytetrafluoroethylene (PTFE) composites using pin on disk configuration. A plan of experiments based on Taguchi $\mathrm{L}_{27}\left(4^{3}\right)$ orthogonal array $(\mathrm{OA})$ was designed to collect data in a controlled manner. The Taguchi $\mathrm{L}_{27}\left(4^{3}\right)$ was hybridized with Deng model to produce grey relational grades (GRG) for the multiple response optimization. Analysis of variance (ANOVA) was executed to establish the parameters affecting GRG of the composites. For the prediction of the tribological behaviours of the composites namely coefficient of friction $(\mu)$ and specific wear rate $\left(\mathrm{K}_{\mathrm{s}}\right)$, support vector regression (SVR) was coupled with novel Harris Hawks' optimization (HHO) and swarm particle optimization (PSO) forming SVR-HHO and SVR-PSO models respectively, were employed. Prediction accuracy of the models were appraised using coefficient of determination $\left(\mathrm{R}^{2}\right)$, correlation coefficient $(\mathrm{R})$, root mean square error (RMSE) and mean absolute percentage error (MAPE). GRG results revealed that optimum parameters which reduced tribological behaviours were factor combination L3G1D3S3. ANOVA for GRG reveled that grit size with $68.57 \%$ ranks as the most influential parameter followed by load with $20.57 \%$, followed by distance having a contribution of $7.78 \%$ and finally speed with least contribution of $3.38 \%$ for minimum tribological loss. Validation performed using optimum parameters revealed an enhancement of $55 \%$ in GRG. Prediction accuracy of the single model increase to $19.50 \%$ and $57.08 \%$ on the average for hybrid $\mu$ and Ks models, respectively. Furthermore, SVR-HHO model indicated the higher prediction accuracy of the tribological behaviours of filled PTFE composites as compared to SVR-PSO model. These findings concluded these metaheuristic models are promising in predicting tribological behaviours of filled PTFE composites and thus can serve as a guide in the design and development of tribological materials.
\end{abstract}

\section{Introduction}

Filled polymer matrix composites (PMCs) containing fillers continue to receive significant attention from academics and industries due to their modified mechanical and tribological behaviours than virgin polymers ${ }^{1}$.Polymer based composites showed improved tribological resistance ${ }^{2}$. Of the different kinds of polymers, polytetrafluoroethylene (PTFE) filled with carbon or bronze fibres are widely used due to their high mechanical and low tribological behaviours ${ }^{3}$. It has been indicated that these composites are suitable in sectors where mechanical parts including brakes and clutches tribological behaviours are significant ${ }^{4-7}$. It has been generally agreed that tribological resistance of materials can be improved by adding more filler content to a certain limit ${ }^{8,9}$ to neat polymers. Polytetrafluoroethylene (PTFE) has been one of the commonly used thermoplastic matrices for wear conditions because of its low coefficient of friction, ease of process-ability, chemical inertness, low density and low-cost 10,11 .

Wear is one of the most commonly encountered problems in industries causing frequent substitution of parts especially abrasion. Abrasive wear of various polymers and filled polymers have been studied experimentally. Abrasive wear rate of different matrices were studied by ${ }^{12}$ and it was found that different polymer exhibited dissimilar wear rate. Inclusion of glass and carbon fabric into vinyl/ester were analyzed. It was reinforced vinyl/ester combination indicated lower wear rate than glass and/or carbon fabric reinforced vinyl/ester composite ${ }^{13}$. As reported by ${ }^{14}$ applied load found as the most significant process parameter; reduced wear rate was observed when performance UHMWPE was reinforced with fillers. According to ${ }^{15}$ it seen that mass loss and $\mu$ increased with increase in speed and decrease in grit sizes for betelnut filled epoxy composites.

In order to study multiple responses related to tribological behaviours of composites several decisionmaking methods including data development, analytic hierarchy as well as grey relational analysis (GRA) have been proposed in the literature ${ }^{16}$. Of these models, GRA proposed by Deng in 1989 is the widely used methodology especially when the nature of the information is not certain and complete ${ }^{17}$. Dharmalingam, Subramanian and Kok combined grey relational analysis (GRA) with Taguchi to optimize abrasive tribological property of aluminium hybrid metal composites. Analysis of variance (ANOVA) indicated that grit size was the 
parameter that had the most influence on wear rate and load was found to had the greatest effect on coefficient of friction ${ }^{18}$. Sylajakumar, Ramakrishnasamy and Palaniappan (2018) used Taguchi-GRA method to study the effect of load, speed and distance on coefficient of friction and wear rate of co-long composite. ANOVA showed that speed significantly affect the wear property of the co-continuous composite ${ }^{19}$. Savaran and Thanigaivelan (2021) optimized dimple geometry and laser parameter using principal component analysis (PCA) coupled GRA. ANOVA showed that average power contributed most while depth contributed less to performance measures ${ }^{20}$.An integrated Taguchi OA and GRA method has been applied to optimize injection moulding parameters of HDPE$\mathrm{TiO} 2$ nanocomposites Pervez and co ${ }^{21}$. The work established that optimum parameters were content of $\mathrm{TiO}_{2}$ at $5 \%$, barrel temperature of $225^{\circ} \mathrm{C}$, residence time of 30 minutes and holding time of $20 \mathrm{~s}$. Adediran et al. optimized mechanical properties of hybrid propylene reinforced bio composites using Taguchi model. It was found that collage of 4\% PSS and 10\% kenaf fibre produced the optimum combination for hybrid bio composites ${ }^{22}$. Besides this, Taguchi method hybridized with grey relational grade has as well been employed for multi-response optimization of wire discharge electrical discharge machining ${ }^{23}$, turning process ${ }^{24}$ and milling parameter ${ }^{25}$.

Due to nonlinearity and complex nature of tribological behaviour of materials soft computing methods are increasingly widely accepted including support vector machine (SVM), adaptive neuro-fuzzy inference system (ANFIS) and artificial neural network (ANN). The reason being the fact that these models are capable of capturing the nonlinear and complex nature of the relation between the tribological parameters and responses as compared to conventional mathematical techniques at much cheaper running costs. Various forms of wear are encountered such as abrasion, adhesive, fretting and fatigue wear. Abrasive tribology for composites, instruments, coatings, hip implant, airplane manufacturing as well as automotive components are of essential importance as it determines parts' performance or longevity. This in general is checked experimentally, as process parameters such as materials characteristics, surface texture, sliding speed and sliding speed. In the analysis of tribology, many mathematical modeling methods have been built. Among them are atomic and molecular kinetics, finite element method, symptom modelling, continuum mechanics, dimension reduction, analysis, boundary element system, stochastic models ${ }^{26}$. Nevertheless, since tribological behaviours are complex and nonlinear, mathematical models are limited.

Lately, the use artificial intelligent (AI) models has become widely accepted in tribology. Jones et al. pioneered the use of ANN to predict life data and tribological behaviours. Accurate prediction of tribological property by ANN gives an option to the present time, cost and energy consuming testing approaches. Since then, the method has been successfully applied in the tribology discipline that includes wear of reinforced polymer composites ${ }^{27,28}$, coefficient of friction and mechanical properties, respectively ${ }^{29,30}$, compensation of magnetic levitation using ANN based on fuzzy inference ${ }^{31}$. ANFIS and ANN were compared in the prediction of $\mathrm{K}_{\mathrm{s}}$ PTFE and its composites. It was found that ANN performed better than ANFIS ${ }^{32}$. Prediction of abrasive wear of industrial waste and glass filled polyester composites was done using ANN and linear regression model. The results found that ANN outperformed the linear model ${ }^{33}$. SVM has been employed in the prediction of tool wear appraisal ${ }^{34,35}$. Also SVM, RBFF and ANN have been contrasted to predict diameter of PCL/.gelatin materials. It was reported that ANN did better than SVR and RBFF put together ${ }^{36}$. Response surface methodology, ANN$\mathrm{HHO}$ as well as model was used in the prediction of abrasive wear of ultrahigh strength martensitic steel. It was reported that hybridized ANN-HHO showed better performance than the single ANN model ${ }^{37}$.

A survey of the reported literature on the database Scopus yielded the finding that there were 450 peerreviewed papers starting from 1989 up to date adopted over the literature using the feasibility of wide interest for the abrasive tribology of PTFE based composites. Figure 1b shows 388 keywords occurrence between those studies, indicating the deep interest and implementation of this field. In addition, the popularity of this study topic was investigated in different regions throughout the world, with the bulk of the countries producing the output being the China, the United States, and India. (Figure 1a). The motivation of this study demonstrated excellent AI techniques for predictions abrasive tribology of filled PTFE composites. Generally each study has progressed to a little higher degree of accuracy for observations and efficiency at a deeper level than the previous one. To the best knowledge of the authors, no study published in a technical literature has predicted the abrasive tribology of PTFE based composites employing this approach using small amount of data. As a result, the goal of this work is to optimize and predict multi-response variable of abrasive wear of reinforced PTFE composites. 


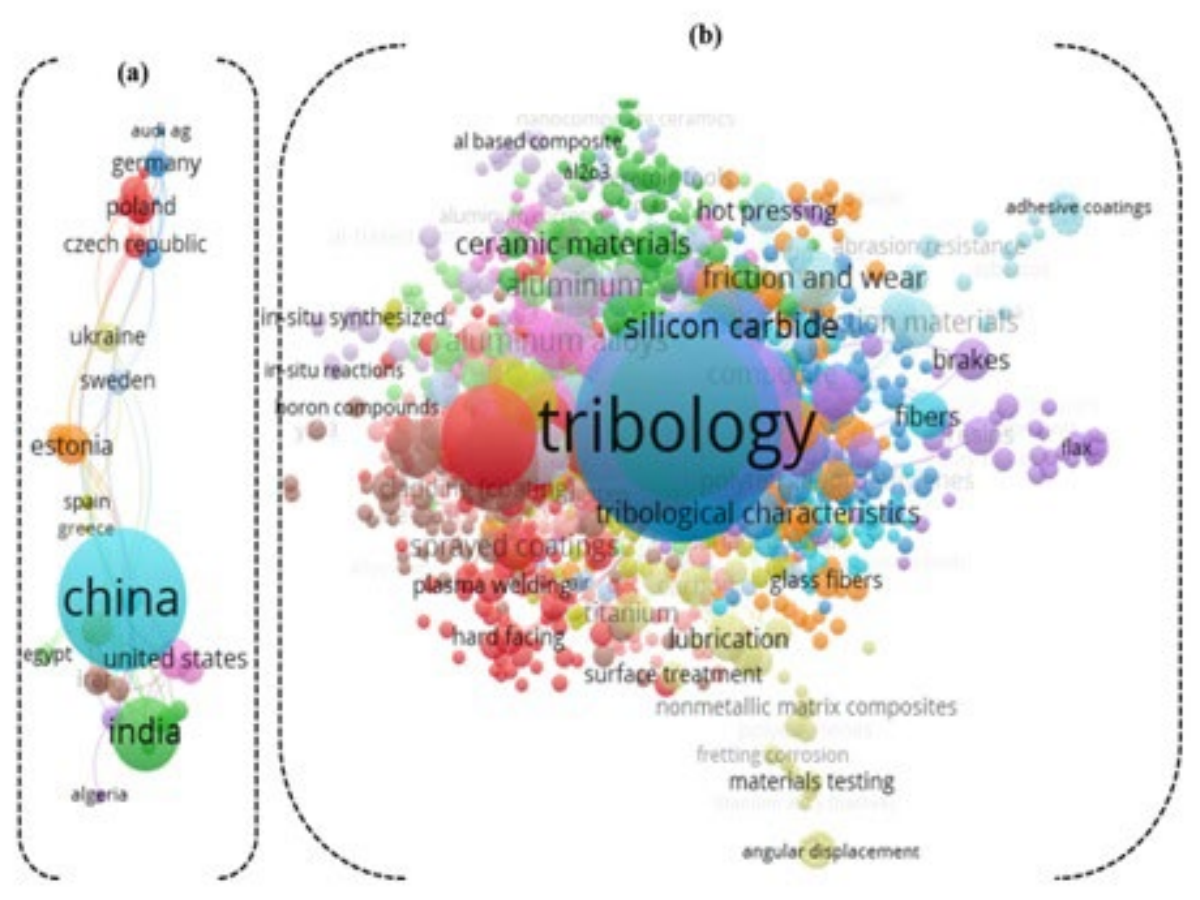

Figure 1. a) Major keywords used over the literature on the abrasive tribology of PTFE based composites field (1989-2021), b) the investigated the research region for abrasive.

\section{Results and Discussion}

\begin{tabular}{|c|c|c|c|c|}
\hline & Experimental results & Experimental results & Signal to Noise Ratio & Signal to Noise Ratio \\
\hline Trial & $\mu$ & ${\text { Ks }\left(\mathrm{mm}^{3} \mathrm{~N}^{-1} \mathrm{~m}^{-1}\right)}^{\prime}$ & $\mu$ SNR $(\mathrm{dB})$ & Ks $(\mathrm{dB})$ \\
\hline 1 & 0.1115 & $8.5700 \mathrm{E}-06$ & 19.05 & 101.74 \\
\hline 2 & 0.2485 & $1.3333 \mathrm{E}-05$ & 12.09 & 97.91 \\
\hline 3 & 0.1695 & $9.8361 \mathrm{E}-06$ & 8.83 & 92.07 \\
\hline 4 & 0.1930 & $1.7284 \mathrm{E}-05$ & 14.29 & 95.65 \\
\hline 5 & 0.2790 & $2.2584 \mathrm{E}-05$ & 11.09 & 93.34 \\
\hline 6 & 0.2865 & $6.9217 \mathrm{E}-06$ & 28.18 & 103.82 \\
\hline 7 & 0.1335 & $1.1977 \mathrm{E}-05$ & 17.49 & 98.84 \\
\hline 8 & 0.2265 & $1.7443 \mathrm{E}-05$ & 12.90 & 95.58 \\
\hline 9 & 0.5330 & $1.8281 \mathrm{E}-05$ & 10.57 & 91.08 \\
\hline 10 & 0.2735 & $4.6737 \mathrm{E}-06$ & 11.26 & 107.01 \\
\hline 11 & 0.2025 & $1.5357 \mathrm{E}-06$ & 13.87 & 116.69 \\
\hline 12 & 0.2220 & $3.8251 \mathrm{E}-06$ & 10.46 & 115.86 \\
\hline 13 & 0.3035 & $3.4632 \mathrm{E}-06$ & 10.36 & 109.61 \\
\hline 14 & 0.1265 & $6.7258 \mathrm{E}-06$ & 17.96 & 112.50 \\
\hline 15 & 0.9595 & $6.2096 \mathrm{E}-06$ & 13.07 & 93.85 \\
\hline 16 & 0.1115 & $2.1261 \mathrm{E}-05$ & 19.05 & 91.38 \\
\hline 17 & 0.5565 & $2.8293 \mathrm{E}-05$ & 5.09 & 88.89 \\
\hline 18 & 0.4475 & $1.9563 \mathrm{E}-05$ & 22.38 & 111.05 \\
\hline 19 & 0.3680 & $2.9341 \mathrm{E}-06$ & 8.68 & 111.14 \\
\hline 20 & 0.0335 & $2.9071 \mathrm{E}-06$ & 29.50 & 116.02 \\
\hline 21 & 0.0490 & $2.0864 \mathrm{E}-06$ & 12.18 & 100.83 \\
\hline 22 & 0.0855 & $9.5238 \mathrm{E}-06$ & 21.36 & 98.35 \\
\hline 23 & 0.1155 & $1.2683 \mathrm{E}-05$ & 18.75 & 104.74 \\
\hline 24 & 0.2805 & $8.3789 \mathrm{E}-06$ & 12.08 & 104.76 \\
\hline 25 & 0.4025 & $6.0553 \mathrm{E}-06$ & 7.90 & 99.11 \\
\hline 26 & 0.2885 & $1.1623 \mathrm{E}-05$ & 10.80 & 110.76 \\
\hline 27 & 0.3075 & $1.0403 \mathrm{E}-05$ & 14.33 & 729 \\
\hline
\end{tabular}

Table 1. Experimental results and their corresponding SNRs of filled PTFE composites based on Taguchi $L_{27}\left(3^{4}\right)$ OA. 


\section{Experimental results}

The results of the tribological experiments for the various test conditions are shown in Table 1. It was seen that the tribological behaviours of the samples indicated rise and fall trend with varying the parameters. Each trial was performed twice and the average was used for the calculations. Highest SNRs of $\mu$ and $\mathrm{K}_{\mathrm{s}}$ occurred at 20 and 12 trials, respectively. These give the minimum tribological rate of the filled PTFE composites. In spite of the fact the temperature was not computed, the temperature increased as the sliding distance increased. Data in Table 1 was used for the calibration and validation of the SVR, SVR-PSO and SVR-HHO models.

\section{Effect of load on $K_{s}$ and $\mu$}

The results of the $\mu$ and Ks are shown in Fig. 2 (a) and (b), respectively. It was observed that as the load increase the $\mu$ and Ks decrease. The low $\mu$ at maximum load is because of the formation tribolayer by the fibres at interacting state as well as temperature and visco-elastic related behaviour. This layer prevented the pin samples to be in direct contact with the abrasive surface. Similar observation was observed by ${ }^{38}$. At $6 \mathrm{~N} \mu$ was high perhaps due to tearing of the fibre tribo layer at the contact region. This finding was contrary to results obtained by ${ }^{39}$. $\mathrm{K}_{\mathrm{s}}$ was low at high load because of great increase in apparent contact area at higher loads thereby leading to increase in contact area permitting a large number of particles to meet the interface and share the stress. This, in turn, reduced the wear rate.

\section{Effect of abrasive size on $\boldsymbol{\mu}$ and $\mathrm{K}_{\mathrm{s}}$}

As shown in Fig. 2(b) increase in abrasive sizes decrease the both $\mu$ and $\mathrm{K}_{\mathrm{s}}$. High $\mu$ at small grit size is related to high roughness of $\mathrm{SiC}$ particles that offered significant amount of resistance while the low $\mu$ is attributed to smoothness of the $\mathrm{SiC}$ particles that offered little resistance to the materials all due to formation of protective layer at contact surface. Decrease in wear rate due to increase in abrasive size is related to clogging of the wear track with wear debris and reduction in cutting efficiency of the abrasives due to transfer.

\section{Effect of sliding distance on $\mu$ and $K_{s}$}

Fig. 2 (a) and (b) shows the relationship between the parameters and the $\mu$ and $\mathrm{Ks}$, respectively. As observed in the figure, increasing the sliding distance increase the $\mu$ while a decrease in Ks observed. This is explained on the basis that distance acted as a lubricant to rubbing surfaces and therefore separated pin specimens from the counter front. Ks reduction due to increase in sliding distance is attributed to pull out or fracture of abrasives as a result of presence of tough fibres. Additionally, wear debris is transferred to counterface from the PTFE causing reduced wear rate.

\section{Effect of sliding speed on $\mu$ and $K_{s}$}

As the sliding speed increase $\mu$ as well as $\mathrm{K}_{\mathrm{s}}$ decrease and high $\mu$ and $\mathrm{Ks}$ are noticed at low speed due to samples' increased contact time with the counterface (Fig. 2(a) and (b). As the rotation rate increases and the samples are oxidized, the temperature at the contacting surfaces changes. This aids formation of a mechanically mixed and rough coating which is laid on the parts. This coating is impervious to removal and depreciates the $\mu$ and Ks significantly. When the surface of the counterface is less touched and the protection of the hard layer is heavily mixed tribological behaviours are reduced. It has been shown that reduction in wear rate depends on production of adherent, uniform and thin hard layer on the counter front ${ }^{40,41}$. Similar results were reported in the studies of $40,42,43$.

In all the analysis, it was found that addition of bronze and carbon fillers into PTFE improved the virgin PTFE's tribological rate. This might be attributed to stiffness and hardness of the fillers. However, BF40 composites showed a slightly lower wear resistance than CF25 composites. This is explained on this basis of the higher weight percentage of the bronze particles that induced more hardness and larger size about $6 \mu \mathrm{m}$. 

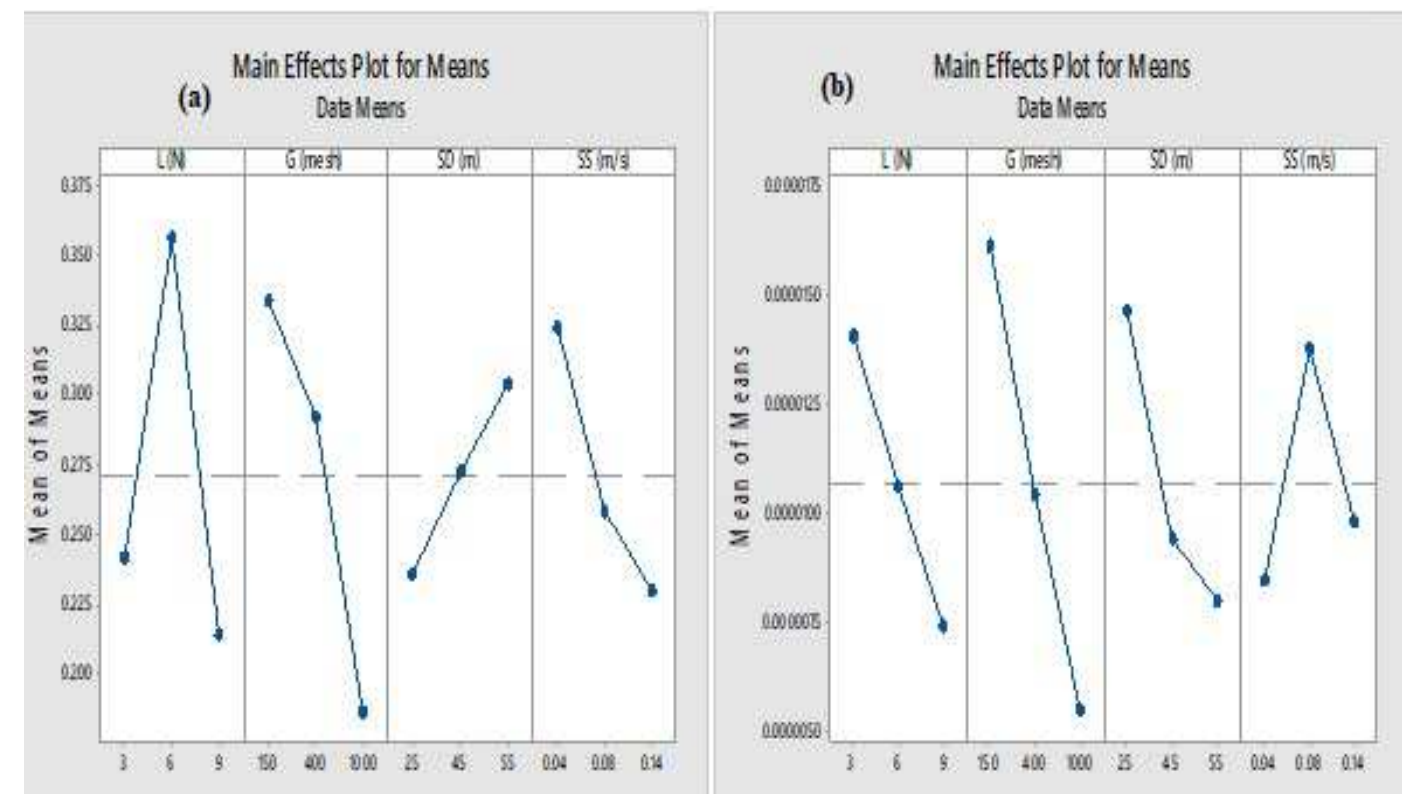

Figure 2. Main effect plot for mean (a) $\mu$ and (b) $\mathrm{K}_{\mathrm{s}}$ of filled PTFE composites.

\section{Results using Taguchi approach}

The experimental data in Table 1 was transformed into signal to noise ratios (SNRs) using equation 4 and the corresponding SNRs was as shown in Table 1. Larger SNRs indicate the minimum variation difference between wanted response and measured response. The maximum value of SNRs at the main effect plot for SNRs give the desired results. Fig. 3(a) and (b) shows the mean SNRs of $\mu$ and $K_{s}$, respectively. Table 2 (a) and (b) presents the computed mean SNRs for the $\mu$ and Ks, respectively. As seen in Fig. 3(a), the maximum mean SNR achieved for $\mu$ were load at $9 \mathrm{~N}$, grit size at 1000 mesh, sliding distance at $25 \mathrm{~m}$ and sliding speed at $0.14 \mathrm{~ms}^{-1}$. Thus, the estimated optimum parameters for achieving a minimum $\mu$ via Taguchi optimization can be coded as L3G1D1S3. For the $\mathrm{K}_{\mathrm{s}}$ (Table 2(b) and Fig. 3(b)), the highest mean SNR obtained for $\mathrm{K}_{\mathrm{s}}$ were load at $9 \mathrm{~N}$, grit size at 1000 mesh, sliding distance at $55 \mathrm{~m}$ and sliding speed at $0.04 \mathrm{~ms}^{-1}$. Therefore, by Taguchi method the predicted optimum parameters are styled as L3G1D3S1. ANOVA depicts the parametric setting that significantly influence the abrasive behaviours. Similarly, the important parametric factor that significantly affect the $\mu$ were found as grit size followed by load, distance and speed 3(a). The percentage contribution of grit size, load, distance and speed were computed as $37.24 \%, 33.92 \%, 17.62 \%$ and $11.20 \%$, (Table 3(a)). Table 2(b) shows the percentage contribution of the parameters on Ks. As seen grit size contributed $51.06 \%$, load contributed $24.65 \%$ SD contributed $22.57 \%$ and speed contributed $1.72 \%$ implying that grit size most significantly influence the $\mathrm{K}_{\mathrm{s}}$ followed by load, distance and speed, respectively.

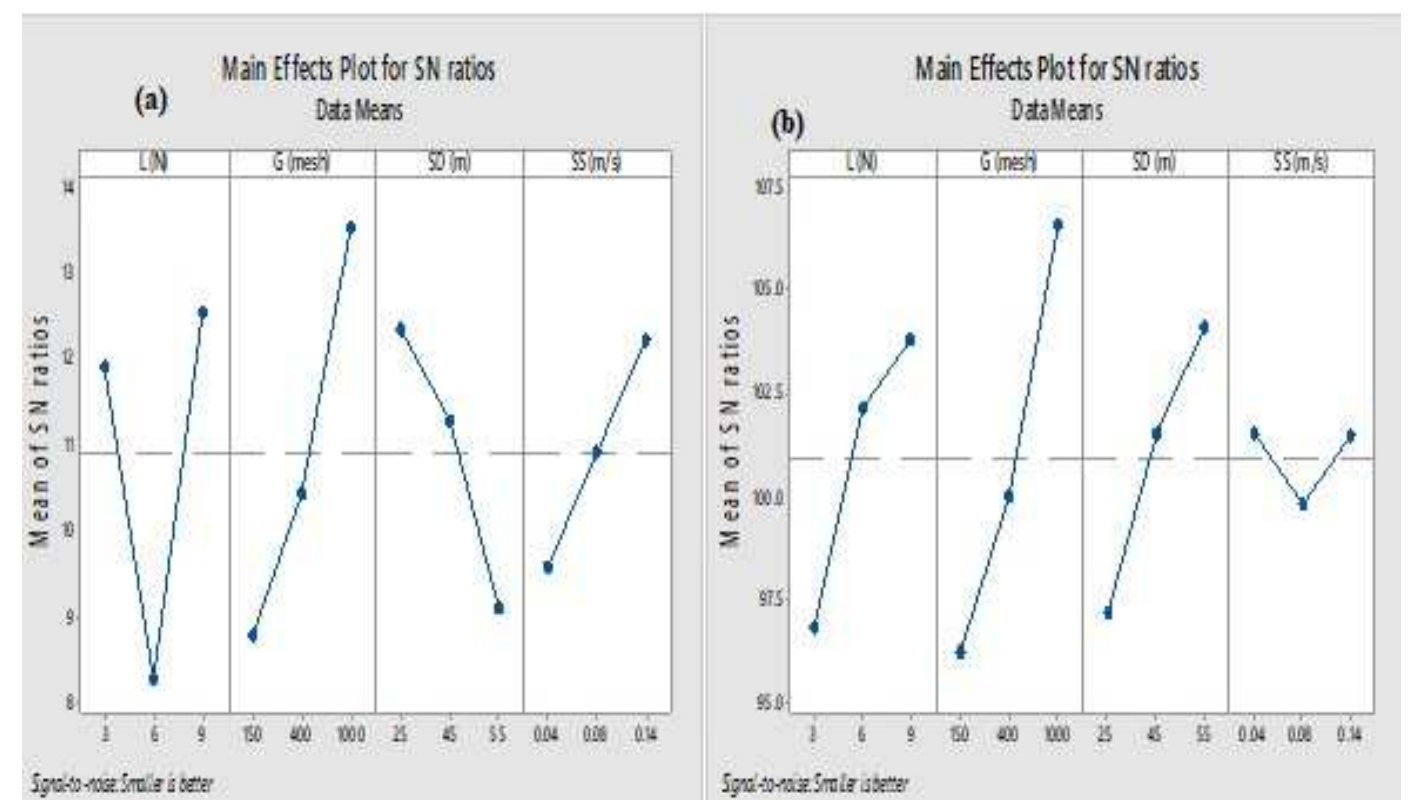

Figure 3. Main effect plot for SNRs of (a) $\mu$ and (b) Ks. 


\begin{tabular}{|c|c|c|c|c|c|c|c|c|}
\hline \multicolumn{5}{|c|}{ Table 2 (a) } & \multicolumn{4}{|c|}{ Table 2 (b) } \\
\hline Level & $\mathrm{L}(\mathrm{N})$ & G (mesh) & $\mathrm{SD}(\mathrm{m})$ & $\mathrm{SS}\left(\mathrm{ms}^{-1}\right)$ & $\mathrm{L}(\mathrm{N})$ & G (mesh) & $\mathrm{SD}(\mathrm{m})$ & $\mathrm{SS}\left(\mathrm{ms}^{-1}\right)$ \\
\hline 1 & 11.92 & 8.78 & 12.35 & 9.59 & 96.88 & 96.26 & 97.23 & 101.54 \\
\hline 2 & 8.28 & 10.42 & 11.29 & 10.92 & 102.16 & 100.03 & 101.54 & 99.85 \\
\hline 3 & 12.53 & 13.53 & 9.09 & 12.3 & 103.82 & 106.57 & 104.09 & 101.47 \\
\hline Delta & 4.27 & 4.75 & 3.25 & 2.64 & 6.94 & 10.31 & 6.86 & 1.69 \\
\hline Rank & 2 & 1 & 3 & 4 & 2 & 1 & 3 & 4 \\
\hline
\end{tabular}

Table 2. Response Table for SNRs of (a) $\mu$ and (b) $K_{s}$.

Optimization using hybrid Taguchi model

As seen above, Taguchi can only optimize a parameter at a time and thus it involves more cost, time and effort. Therefore, Deng widely called Grey relational analysis (GRA) is principally used to optimize multiple parameters by combining all outputs into an output. Deng is used to unravel real problems made up of a bounded amount of data. It is commonly employed to approximate the properties of indefinite systems having no black and white solution. With respect to grey system black signifies without information whereas white connotes with information. This technique is largely utilized to maximize or minimize problems which have to do with several factors and responses. Data preprocessing through GRA was executed on test data of responses in Table 1 i.e. $\mu$ as well as Ks. Table 3 shows the reference sequence obtained by normalization (equation 5). In due course, the deviation sequence was computed following equation 6 (Table 3). Grey relation coefficient (GRC) and grey relational grade (GRG) of $\mu$ as well as Ks were determined using equations 6 and 7, respectively. Subsequently, the mean of GRCs is calculated to establish the GRG. Calculated values of GRGs were employed to produce equivalent SNRs. A larger magnitude of SNR is useful alluding the tests lay in proximity to the actual normalized magnitude of GRG. Fig. 4 depicts the plot of GRG against SNRs. It indicates that the 21 st trial possesses the highest SNR. Correspondingly, the first rank was designated to 21st trial. The straggling disposition of the GRG, below the plot of SNRs in Fig. 4, also adds to the aforementioned explanation. Ever the ranks determined (Table 5), GRG response table was contrived. Individual factor of GRG at the preferred level was chosen as well as average computed to obtain the mean GRG for separate parameters. The mean response table for the GRG is presented in Table 6.

For example, variable $\mathrm{G}$ at level 1 in the first, fourth and seventh runs of the test. The concomitant GRG values in Table 5 were used for computation using equation 8 . The mean of the chosen GRGs was computed through the method aforementioned put together to generate the mean response table (Table 5). The grades in the response table is used as a degree of correlation ${ }^{44}$. Hence, from Table 5 , it is possible to achieve combination of optimum parameters which maximize the overall response. As observed in Table 5, the maximum GRG exists at L3, G1, D3 and S3. Therefore, to wrap it up, the best parameter settings for useful abrasive tribological behaviours of filled PTFE composites are load at $9 \mathrm{~N}$, grit size at $1000 \mathrm{mesh}$, distance at $55 \mathrm{~m}$ and sliding speed at $0.14 \mathrm{~ms}^{-1}$ coded as L3G1D3S3. ANOVA for GRG shows that grit size with $68.57 \%$ ranks as the most influential followed by load with $20.57 \%$, followed by distance having a contribution of $7.78 \%$ and finally speed with least contribution of $3.38 \%$ for minimum tribological loss.

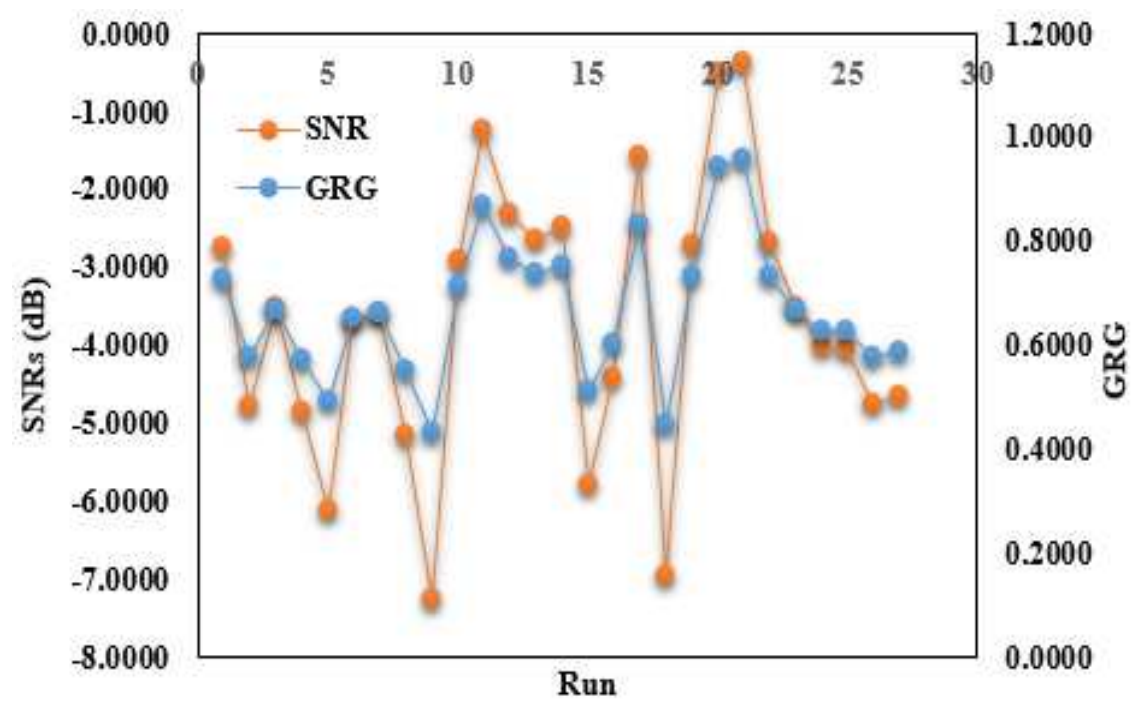

Figure 5. GRG versus SNRs plot. 


\begin{tabular}{|c|c|c|c|c|}
\hline & Reference sequence & Reference sequence & Deviation sequence & Deviation sequence \\
\hline Run & $\mu$ & Ks & $\mu$ & $\mathrm{Ks}$ \\
\hline 1 & 0.9158 & 0.6657 & 0.0842 & 0.2629 \\
\hline 2 & 0.7678 & 0.4395 & 0.2322 & 0.4409 \\
\hline 3 & 0.8531 & 0.6056 & 0.1469 & 0.3102 \\
\hline 4 & 0.8278 & 0.2518 & 0.1722 & 0.5886 \\
\hline 5 & 0.7349 & 0.0000 & 0.2651 & 0.7866 \\
\hline 6 & 0.7268 & 0.7441 & 0.2732 & 0.2013 \\
\hline 7 & 0.8920 & 0.5039 & 0.1080 & 0.3902 \\
\hline 8 & 0.7916 & 0.2442 & 0.2084 & 0.5945 \\
\hline 9 & 0.4606 & 0.2044 & 0.5394 & 0.6258 \\
\hline 10 & 0.7408 & 0.8509 & 0.2592 & 0.1173 \\
\hline 11 & 0.8175 & 1.0000 & 0.1825 & 0.0000 \\
\hline 12 & 0.7964 & 0.8912 & 0.2036 & 0.0856 \\
\hline 13 & 0.7084 & 0.9084 & 0.2916 & 0.0720 \\
\hline 14 & 0.8996 & 0.7534 & 0.1004 & 0.1940 \\
\hline 15 & 0.0000 & 0.7779 & 1.0000 & 0.1747 \\
\hline 16 & 0.9158 & 0.0624 & 0.0842 & 0.7375 \\
\hline 17 & 0.7910 & 0.9840 & 0.2090 & 0.0160 \\
\hline 18 & 0.5529 & 0.1435 & 0.4471 & 0.6737 \\
\hline 19 & 0.6388 & 0.9336 & 0.3612 & 0.0523 \\
\hline 20 & 1.0000 & 0.9348 & 0.0000 & 0.0513 \\
\hline 21 & 0.9833 & 0.9738 & 0.0167 & 0.0206 \\
\hline 22 & 0.9438 & 0.6205 & 0.0562 & 0.2985 \\
\hline 23 & 0.9114 & 0.4704 & 0.0886 & 0.4166 \\
\hline 24 & 0.7333 & 0.6749 & 0.2667 & 0.2558 \\
\hline 25 & 0.6015 & 0.7853 & 0.3985 & 0.1689 \\
\hline 26 & 0.7246 & 0.5207 & 0.2754 & 0.3770 \\
\hline 27 & 0.7041 & 0.5787 & 0.2959 & 0.3314 \\
\hline
\end{tabular}

Table 3. Reference and deviation sequences post data processing.

\begin{tabular}{|c|c|c|c|c|}
\hline Level & $\mathrm{L}(\mathrm{N})$ & $\mathrm{G}(\mathrm{mesh})$ & $\mathrm{SD}(\mathrm{m})$ & $\mathrm{SS}_{\left(\mathrm{ms}^{-1}\right)}$ \\
\hline 1 & 0.6218 & 0.5687 & 0.6315 & 0.6665 \\
\hline 2 & 0.6620 & 0.6651 & 0.6733 & 0.6635 \\
\hline 3 & 0.7391 & 0.7890 & 0.7181 & 0.6929 \\
\hline Delta & 0.1173 & 0.2203 & 0.0867 & 0.0294 \\
\hline Rank & 2 & 1 & 3 & 4 \\
\hline
\end{tabular}

Table 6. Response table for GRGs. 


\begin{tabular}{|c|c|c|c|c|}
\hline Grey relational coefficient & Grey relational coefficient & & & \\
\hline$\mu$ & Ks & Grey relational grade & $\operatorname{SNRs}(\mathrm{dB})$ & Rank \\
\hline 0.8558 & 0.5993 & 0.7276 & -2.7625 & 10 \\
\hline 0.6829 & 0.4715 & 0.5772 & -4.7738 & 21 \\
\hline 0.7730 & 0.5591 & 0.6660 & -3.5304 & 13 \\
\hline 0.7438 & 0.4006 & 0.5722 & -4.8494 & 22 \\
\hline 0.6535 & 0.3333 & 0.4934 & -6.1358 & 25 \\
\hline 0.6466 & 0.6615 & 0.6541 & -3.6877 & 15 \\
\hline 0.8224 & 0.5020 & 0.6622 & -3.5805 & 14 \\
\hline 0.7058 & 0.3982 & 0.5520 & -5.1615 & 23 \\
\hline 0.4810 & 0.3859 & 0.4335 & -7.2606 & 27 \\
\hline 0.6586 & 0.7703 & 0.7145 & -2.9205 & 11 \\
\hline 0.7326 & 1.0000 & 0.8663 & -1.2467 & 3 \\
\hline 0.7107 & 0.8213 & 0.7660 & -2.3155 & 5 \\
\hline 0.6317 & 0.8452 & 0.7384 & -2.6339 & 7 \\
\hline 0.8327 & 0.6697 & 0.7512 & -2.4846 & 6 \\
\hline 0.3333 & 0.6925 & 0.5129 & -5.7994 & 24 \\
\hline 0.8558 & 0.3478 & 0.6018 & -4.4108 & 18 \\
\hline 0.7053 & 0.9609 & 0.8331 & -1.5862 & 4 \\
\hline 0.5279 & 0.3686 & 0.4483 & -6.9692 & 26 \\
\hline 0.5806 & 0.8827 & 0.7316 & -2.7141 & 9 \\
\hline 1.0000 & 0.8847 & 0.9424 & -0.5157 & 2 \\
\hline 0.9676 & 0.9503 & 0.9589 & -0.3642 & 1 \\
\hline 0.8990 & 0.5685 & 0.7338 & -2.6889 & 8 \\
\hline 0.8495 & 0.4856 & 0.6676 & -3.5099 & 12 \\
\hline 0.6521 & 0.6060 & 0.6290 & -4.0264 & 16 \\
\hline 0.5565 & 0.6996 & 0.6280 & -4.0404 & 17 \\
\hline 0.6448 & 0.5106 & 0.5777 & -4.7657 & 20 \\
\hline 0.6282 & 0.5427 & 0.5855 & -4.6499 & 19 \\
\hline
\end{tabular}

Table 4. Rank of GRG with SNRs.

\section{Validation}

Having determined the optimum parameters, the final phase in Taguchi-Deng is prediction as well as validation of performance enhancement of the dual responses. The predicted GRG was calculated as per equation 7. Validation experiments were executed to validate the results of the analysis. Validated results showed that minimum $\mu$ and $\mathrm{K}_{\mathrm{s}}$ were $2.0 \times 10^{-1}$ and $1.5353 \times 10^{-6} \mathrm{~mm}^{3} \mathrm{~N}^{-1} \mathrm{~m}^{-1}$, respectively. More so, it can be implied from Table 5 that the findings of the validation phase are consistent with the computed values. Besides, an enhancement of $55 \%$ in GRG was achieved. This performance enhancement in the results obtained through the experiments over the initial design parameter confirms the validity of the Taguchi-Deng method for studying the abrasive tribological behaviours of filled PTFE composites.

\begin{tabular}{|l|l|l|l|}
\hline & & Optimal parameter & \\
\hline & Initial design parameter & Prediction & Validation \\
\hline Level settings & L1G3D3S1 & L3G1D3S3 & L3G1D3S3 \\
\hline GRG & 0.4335 & 0.9589 & 0.9556 \\
\hline Enhancement (\%) & & 54.56 & 54.66 \\
\hline
\end{tabular}

Table 5. Results of the confirmatory test. 


\section{Performance appraisal of the models}

One of the aims of this work is building hybrid SVR models namely SVR-PSO and SVR-HHO models and compare their efficiency in predicting tribological behaviours of filled PTFE composites. For this objective, tribological behaviours $\left(\mu\right.$ and $\mathrm{K}_{\mathrm{s}}$ ) were obtained via experimental results of Table 1. Prediction of tribological behaviours by traditional methods is time and energy consuming due to nonlinearity between tribological independents and dependents of filled polymer composites leading to inaccuracy. These issues can be addressed by nonlinear models. Subsequently, this section details the results achieved in visualized and graphical forms. Before the models simulations, the data was normalized using equation 16. Data normalization disallows larger values overshadowing lower values, takes care of units and improves the efficiency of the models.

The simulation process was performed in MATLAB 9.3 (R2020 (a)).Optimized structure of SVR model was chosen via trial-and-error approach. An efficient model is that which allays the prerequisites of model appraisal metrics. Prediction efficiency of the models were appraised using two goodness of fit $\left(\mathrm{R}^{2}, \mathrm{R}\right)$ and two prediction error (RMSE, MAPE) metrics in training as well as testing regimes. The simulated outcomes of the individual SVR models for the prediction of $\mu$ and $\mathrm{K}_{\mathrm{s}}$ are quantitatively presented in Table 6 . From Table 6 , it can be seen that the single SVR models achieved various adequacies according to the statistical evaluation metrics. More so, SVR $\mu$ shows best results in terms of goodness of fit in both testing and training stages as compared to $\mathrm{SVR}_{\mathrm{Ks}}$ model. However, with respect to prediction errors SVR $\mathrm{Ks}_{\mathrm{Ks}}$ with RMSE $5 \times 10^{-6}$ and MAPE $29 \%$ proved to be a relatively adequate model in predicting the tribological behaviours of filled PTFE composites than SVR $\mu$ whose accuracy is extremely poor (61\%). To have a graphical map of SVR models for the tribological behaviours, a scatter plot is used. A scatter plot gives the degree of agreement between measured and calculated values for the overall goodness of fit. Fig. 5 (a) and (b) depicts the scatter plot of the whole data for SVR $\mu$ as well as SVR $\mathrm{Ks}_{\mathrm{s}}$ models, respectively. Arising from the scatter plots, it is interesting to note here that SVR $\mathrm{Ks}_{\mathrm{s}}$ model indicated better fitness in comparison to $\mathrm{SVR}_{\mathrm{Ks}}$ when the whole data points were put together.

\begin{tabular}{|c|c|c|c|c|c|c|c|c|}
\hline & Calibration & & & & & & Validation & \\
\hline Models & $\mathrm{R}^{2}$ & $\mathrm{R}$ & RMSE & MAPE & $\mathrm{R}^{2}$ & $\mathrm{R}$ & RMSE & MAPE \\
\hline $\mathrm{SVR}_{\mathrm{Ks}}$ & 0.5919 & 0.7694 & 0.000005 & 0.3938 & 0.5360 & 0.7321 & 0.000003 & 0.2911 \\
\hline $\mathrm{SVR}_{\mu}$ & 0.8026 & 0.8959 & 0.1974 & 0.7914 & 0.8984 & 0.9478 & 0.1016 & 0.6164 \\
\hline
\end{tabular}

Table 6. Results of appraisal for single SVR models of $\mu$ and $K_{s}$.
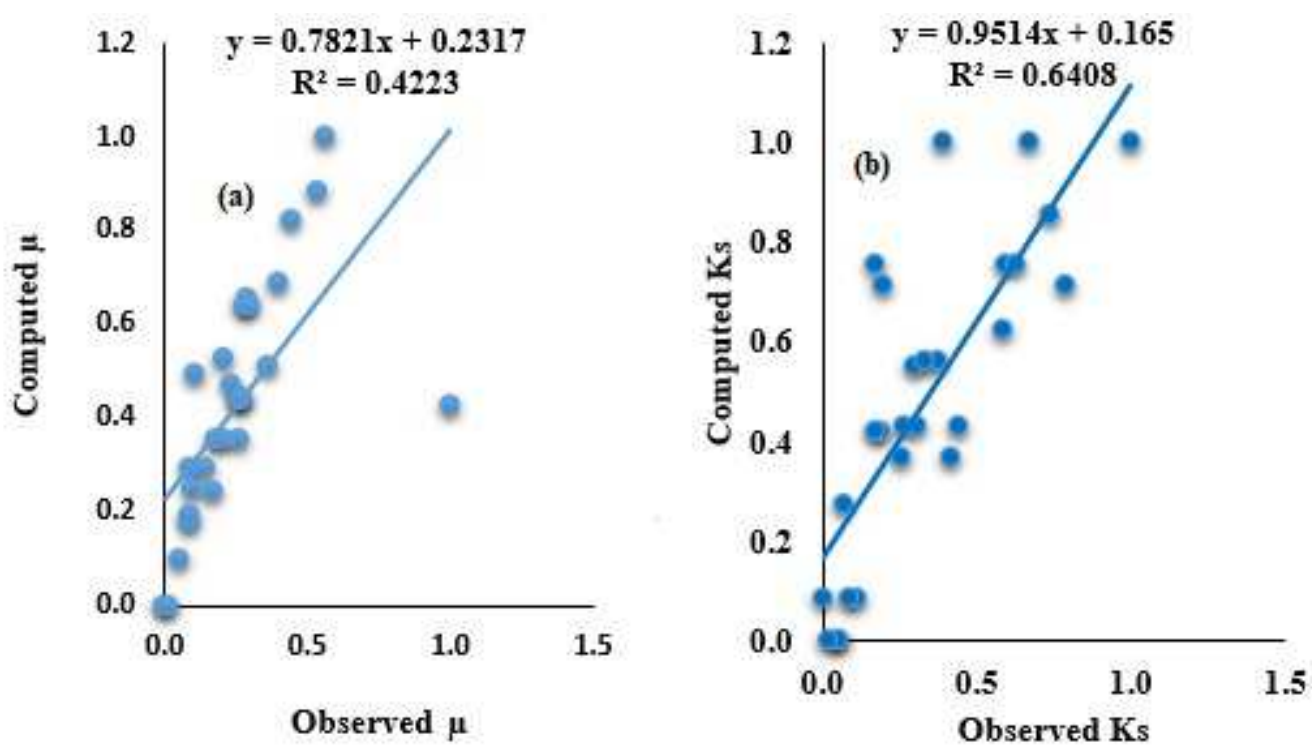

Figure 5. Scatter plot of (a) $\mathrm{SVR}_{\mu}$ model (b) $\mathrm{SVR}_{\mathrm{Ks}}$ model for the whole data.

Nevertheless, overall prediction accuracy of the single SVR models was inadequate, especially for $\mathrm{SVR}_{\mu}$ model. The accuracy can be enhanced using optimization approaches namely PSO and HHO. Fundamentally, it should be considered that the promising prediction accuracy occurred in the course of the training state which is originally used to measure precisely the model based on known inputs and outputs. Nevertheless, the verification stage is significant in appraising the prediction efficiency of the models since it inspects closely the models' prediction accuracy based upon unknown magnitudes. This advantage is not enjoyed by the training phase. Consequently, a robust model should possess determinate and balanced performance in both training and testing 
regimes. In general, hybridized models showed a promising ability when compared to un-hybridized models. For consistency the same model evaluation metrics are used to assess the prediction accuracy of the hybridized models. Table 9 shows the results of the hybrid models in both calibration and validation regimes. In spite of the fact it is hard to rank the models as per the model evaluation criteria, the SVR-HHO model indicated higher prediction accuracy in both conditions. From Table 7, it was observed that $\mathrm{SVR}-\mathrm{HHO}_{\mu \mathrm{s}}$ indicated $\mathrm{R}^{2}>90 \% \mathrm{R}=95 \%, 99.26 \%$, RMSE $>5 \%$, and MAPE of 5\% = Similarly, SVR-HHO $\mathrm{Ks}^{2}>95 \%, \mathrm{R}>97 \%$, RMSE $<1 \%$ as well as MAPE $=3 \%$. This implies SVR-HHO model performed better than SVR-PSO model for prediction of the tribological behaviours of the filled PTFE composites. The predictive superiority of HHO to others is in concord with results obtained by ${ }^{45}$. Fig. 10 presents the scatter plot of the SVR hybrid models. Close consistency between measured and calculated points was achieved for SVR-HHO model as compared to SVR-PSO model. More so, R values of the hybrid models lie between $85-99 \%$. This agrees with conclusions drawn by ${ }^{46-48}$ that values of $\mathrm{R}$ greater than $70 \%$ are regarded as acceptable. Therefore, all the optimized hybrid models are acceptable (Table 7).

\begin{tabular}{|c|c|c|c|c|c|c|c|c|}
\hline & Calibration & & & & Validation & & & \\
\hline Models & $\mathrm{R}^{2}$ & $\mathrm{R}$ & $\mathrm{RMSE}$ & $\mathrm{MAPE}$ & $\mathrm{R}^{2}$ & $\mathrm{R}$ & $\mathrm{RMSE}$ & $\mathrm{MAPE}$ \\
\hline $\mathrm{SVR}_{-P S O}$ & 0.8790 & 0.9376 & 0.1210 & 0.5274 & 0.9221 & 0.9603 & 0.0779 & 0.0513 \\
\hline $\mathrm{SVR}_{\mu} \mathrm{HHO}_{\mu}$ & 0.9123 & 0.9551 & 0.0877 & 0.5139 & 0.9364 & 0.9677 & 0.0636 & 0.0490 \\
\hline SVR-PSO $_{\mathrm{Ks}}$ & 0.8424 & 0.9178 & 0.000003 & 0.1446 & 0.9301 & 0.9644 & 0.000001 & 0.1601 \\
\hline SVR-HHO & $\mathbf{0 . 9 4 6 8}$ & $\mathbf{0 . 9 7 3 0}$ & $\mathbf{0 . 0 0 0 0 0 2}$ & $\mathbf{0 . 0 8 5 7}$ & $\mathbf{0 . 9 8 5 3}$ & $\mathbf{0 . 9 9 2 6}$ & $\mathbf{0 . 0 0 0 0 0 1}$ & $\mathbf{0 . 0 3 2 2}$ \\
\hline
\end{tabular}

Table 7. Findings of appraisal of the hybrid models for predicting for $\mu$ and $K_{s}$.
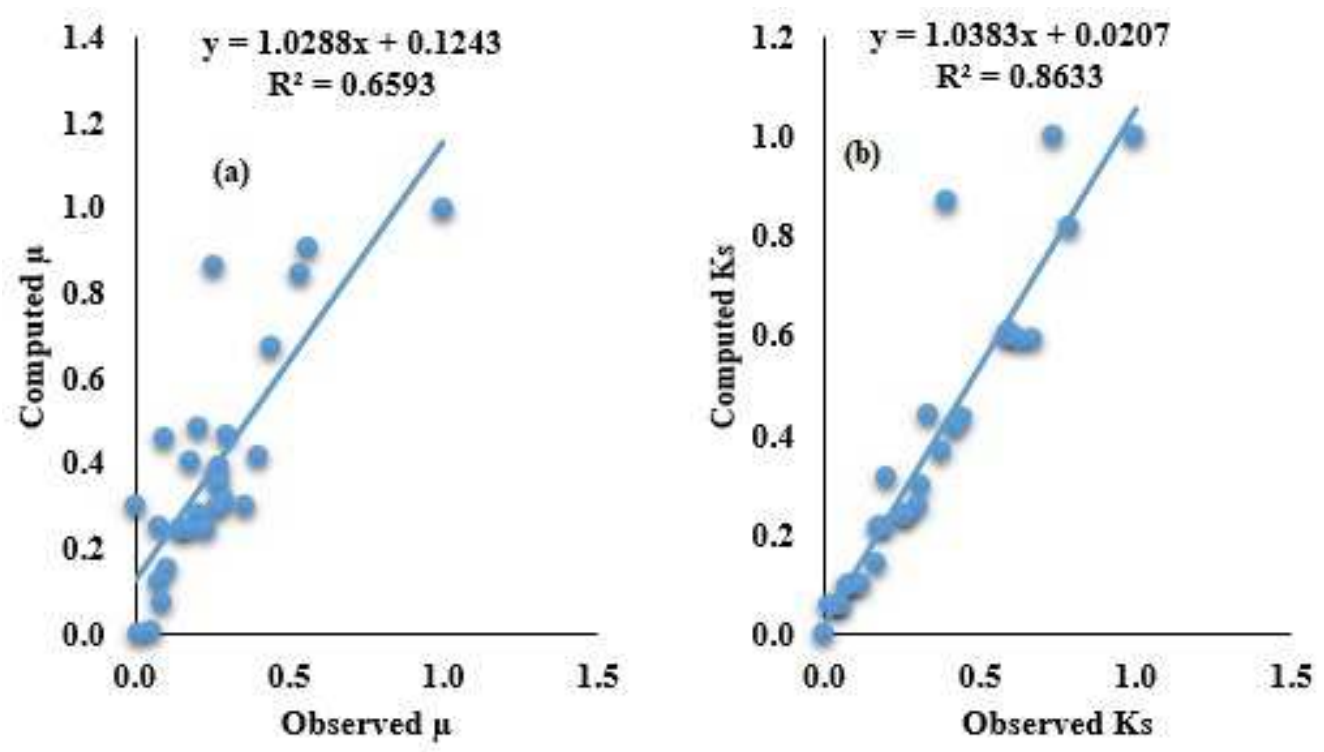

Figure 6. Scatter plot for (a) SVR-PSO ${ }_{\mu}$ and (b) $\mathrm{SVR}^{-H H O} \mathrm{Ks}_{\mathrm{s}}$ models all data sets. 

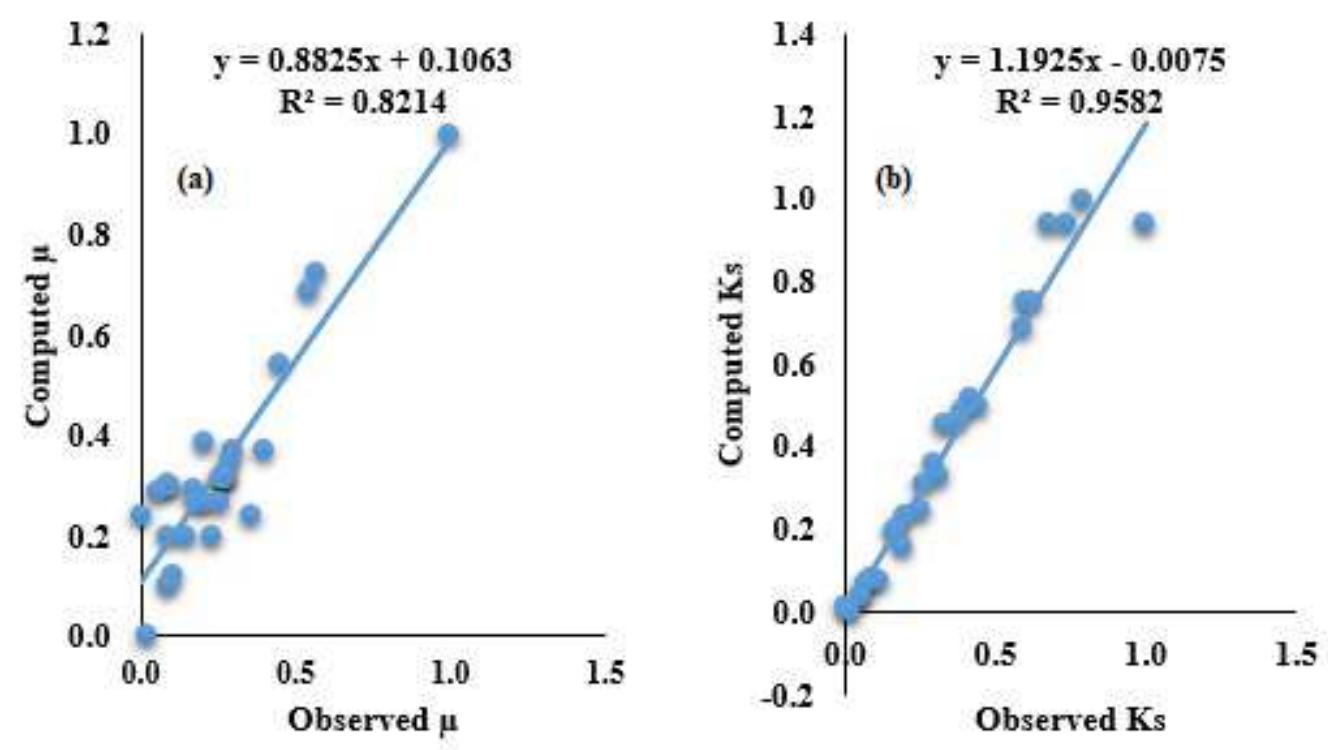

Figure 7. Scatter plot for (a) SVR-PSO $\mu$ and (b) SVR-HHO $\mathrm{Ks}_{\mathrm{s}}$ models for all dataset.

\section{Comparing the performance of the models}

The SVR model and its hybrids namely SVR-PSO and SVR-HHO models are compared via 2D Taylor's plot as shown in Figs. 8 and 9, respectively. As seen in the Taylor's plot SVR-HHO model indicated better fitness in both cases with values of $97 \%$ and $99 \%$ for $\mu$ and $\mathrm{Ks}$, respectively in the calibration regime. Therefore, it can wrapped up that SVR, SVR-PSO and SVR-HHO models can understand and follow the intricate and nonlinear correlation between tribological input parameters and response parameters of filled PTFE composites in abrasive conditions.Additional analysis can be done using a radar plot for the prediction of the $\mu$ and Ks as shown in Fig. 10. It can as well be seen that $\mathrm{SVR}-\mathrm{HHO}_{\mu}>\mathrm{SVR}-\mathrm{PSO}_{\mu}>\mathrm{SVR}_{\mu}$ and $\mathrm{SVR}-\mathrm{HHO}_{\mathrm{Ks}}>\mathrm{SVR}-\mathrm{PSO}_{\mathrm{Ks}}>\mathrm{SVR}_{\mathrm{Ks}}$. This implies that in both cases SVR-HHO model was able of capturing the best fitting trend of the tribological behaviours of filled PTFE composites.
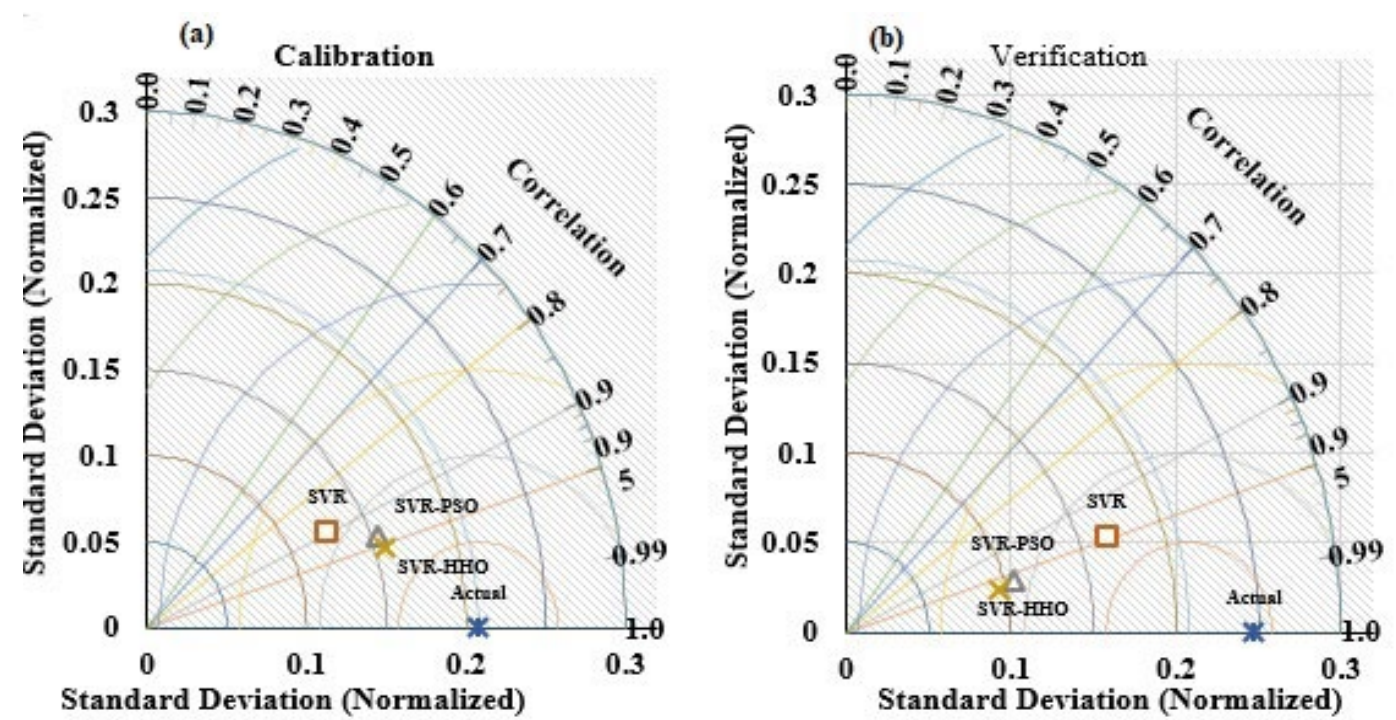

Standard Deviation (Normalized)

Figure 8. Taylor diagram for $\mu$ models in (a) calibration stage and (b) verification stages. 

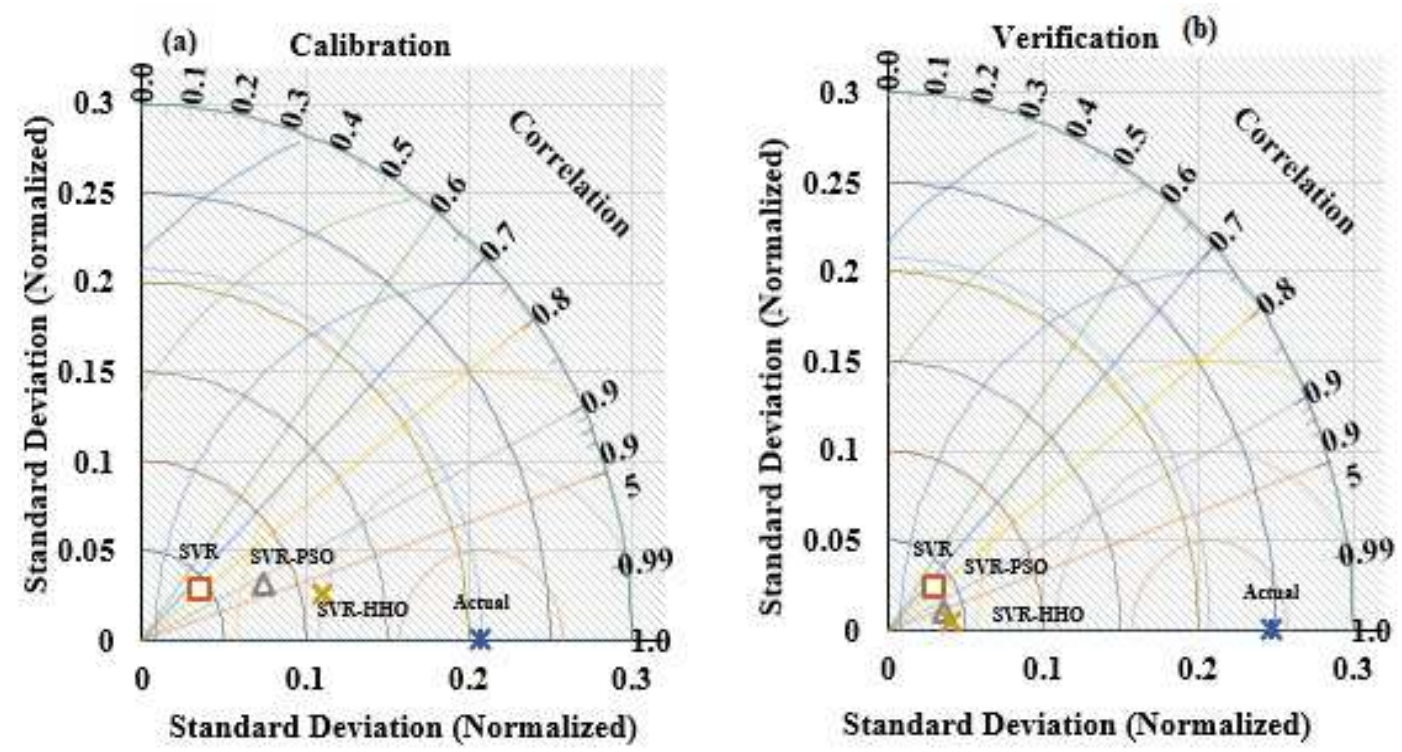

Figure 9. Taylor diagram for $\mathrm{K}_{\mathrm{s}}$ models in (a) calibration and (b) verification of the models.
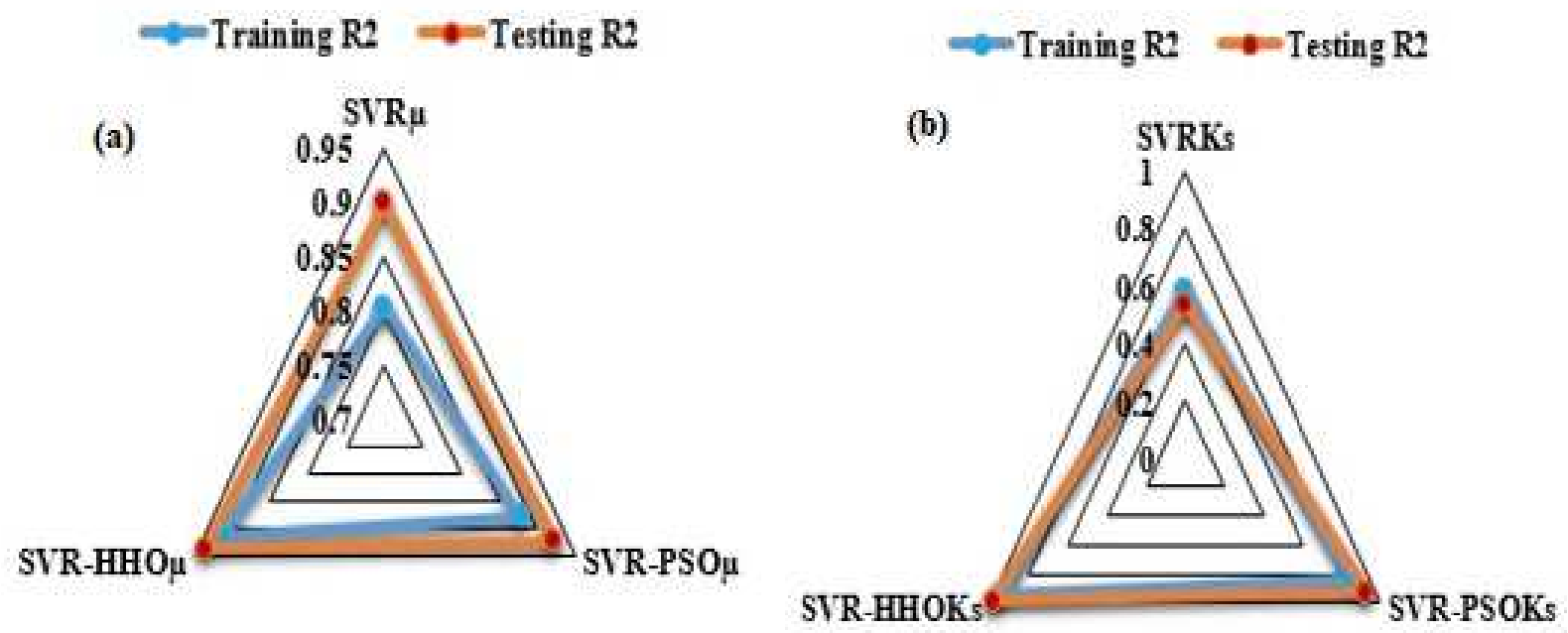

Figure 10. Radar plot for (a) $\mu$ and (b) Ks in calibration and verification regimes.

In spite of the availability of ample of predictive models, there is no particular model that can guarantee consistent optimal performance in addressing various types of issues. Yet, latest research on unique populationbased as well as nature inspired optimization paradigm (HHO) models indicated better adequacy in establishing optimal solutions for multi-objective problems. The statistical analysis outcomes and comparisons revealed that SVR-HHO model yields promising and often competitive outcomes than well-established models.

\section{Conclusions}

This study presents optimization and prediction of tribological behaviours of filled PTFE composites. Firstly, results of four different tribological parameters namely load, grit size, distance and speed on the multiple response of the $\mu$ and Ks were investigated based on Taguchi $\mathrm{L}_{27}\left(3^{4}\right) \mathrm{OA}$ and Deng method. According to the response table of the GRGs optimum parameter levels were found as parameter combination of L3G1D3S3. ANOVA for GRGs indicated that grit size was the most influential parameter affecting tribological behaviours of filled PTFE composites. Validation test revealed that there was an enhancement of $55 \%$ in GRG from 0.4335(L1G3D3S1) for initial design settings to 0.9589 for the optimized levels (L3G1S3D3). SVR model and its hybrids whose inputs were the tribological parameters were built to predict the $\mu$ and Ks. The findings of the hybridized SVR models exhibited an improvement in predictive ability for the un-hybridized SVR models. Even though both SVR-HHO and SVR-PSO models were able to accurately predict the $\mu$ and Ks, SVR-HHO model exhibited the lowest prediction error of $4.06 \%$ on the average as compared to SVR-PSO model whose prediction error was found as $10.57 \%$ on the average. This proves the robustness of SVR-HHO model in predicting $\mu$ and $\mathrm{K}_{\mathrm{s}}$. 


\section{Methods}

\section{Experimental set up}

In this article, Arton Paar tribometer (Made in Switzerland) shown in Fig. 11 was used for the test. The experimental set-up consists of a fixed vertical pin kept perpendicular to a horizontal rotating circular disk. The rectangular pin samples of dimensions $20 \mathrm{~mm}$ long, width $10 \mathrm{~mm}$ and deep $6 \mathrm{~mm}$ were used for the study. The pin was prepared by cutting a plaque of $500 \mathrm{~mm} \times 500 \mathrm{~mm} \times 6 \mathrm{~mm}$ using computer numerical water jet machining. The disk of diameter $80 \mathrm{~mm}$ and a thickness of $20 \mathrm{~mm}$ was used. The chosen loads were transmitted through the arm to keep the samples pressed against the disk. Dirties were cleaned from the pin and the disk before and after every test. The materials utilized in this work were polytetrafluoroethylene (PTFE), carbon-filled composites (CF25) and bronze-filled composites (BF40) because of their availability and wider applications. The weight loss was measured using PS 1000.RS RADWAG digital weighing machine (Made in Poland) with $10^{-3} \mathrm{~g}$ sensitiveness. The test conditions are shown in Table 8.

The experiments were conducted according to ASTM G99 standard using in-house tribometer. The rectangular pins having dimensions as above were prepared from the rectangular plaques of the materials. A small disk of sufficient roughness was utilized as a sliding counterpart. Non-lubricated tribological tests with various control factors such as grit size, load, sliding distance as well as sliding speed were executed. Conditions for the experiment are indicated in Table 1. Before and after the method, the weight of the materials was computed using the analytical balance PS 1000.RS RADWAG of precision $10^{-3} \mathrm{~g} . \mu$ is computed and displayed by the computer attached to the tribometer. The loss in pin weight $(\mathrm{WL})$, volume $(\mathrm{VL})$ and specific wear rake $\left(\mathrm{K}_{\mathrm{s}}\right)$ was determined through the mathematical equations (1), (2) and (3), respectively

\begin{tabular}{|c|c|c|c|c|}
\hline Parameters & Symbol & Level 1 & Level 2 & Level 3 \\
\hline Load, (N) & L & 3 & 6 & 9 \\
\hline Grit, $(\mathrm{mesh})$ & $\mathrm{G}$ & 1000 & 400 & 150 \\
\hline Distance, $(\mathrm{m})$ & $\mathrm{D}$ & 25 & 45 & 55 \\
\hline Speed,$\left(\mathrm{ms}^{-1}\right)$ & $\mathrm{S}$ & 0.04 & 0.08 & 0.14 \\
\hline
\end{tabular}

Table 8. Parameters and their levels.

$$
\begin{aligned}
& \mathrm{WL}=m_{b}-m_{a} \\
& \mathrm{VL}=\frac{\mathrm{M}_{\mathrm{L}}}{\rho} \\
& \mathrm{K}_{\mathrm{S}}=\frac{\mathrm{M}_{\mathrm{L}}}{\rho \mathrm{LD}}
\end{aligned}
$$

Where $\mathrm{W}_{\mathrm{L}}=$ weight loss $(\mathrm{g}), \mathrm{V}_{\mathrm{L}}=$ volume loss $\left(\mathrm{mm}^{3}\right) m_{b}=$ mass before test $(\mathrm{g}), m_{a}=$ mass after test $(\mathrm{g}), \rho=(\mathrm{gcm}-$ ${ }^{3}$ ) of materials, $\mathrm{L}=$ load in $\mathrm{N}$ and $\mathrm{D}=$ sliding distance $(\mathrm{m})$. Each trial was performed twice and averaged.

\section{Taguchi optimization approach}

Single parameter optimization and percentage contribution of each parameter can be performed using Taguchi $\mathrm{L}_{27}\left(3^{4}\right)$ orthogonal array (OA). Taguchi is an optimization process to establish the best process parameter. In this study, four parameters with three levels $\left(3^{4}\right)$ are considered for the configuration of the test. Twenty seven trials have been performed based on Taguchi $\mathrm{L}_{27}\left(3^{4}\right) \mathrm{OA}$ as shown in Table 9. Signal to noise ratios (SNRs) are used to establish the optimum parameters and followed equation 4. SNRs for $\mu$ and Ks can be computed for all the 27 trials in accordance with Taguchi $L_{27}\left(3^{4}\right)$ OA.

$$
(\mathrm{SNR}) \mathrm{STB}=-\log 10 \frac{1}{\mathrm{n}}\left(\sum_{\mathrm{i}=0}^{\mathrm{n}}\left(\mathrm{y}_{i}\right)^{2}\right)
$$

Where $\mathrm{n}=$ number of experiments and $\mathrm{y}_{i}=$ experimental value.

\begin{tabular}{|l|l|l|l|l|}
\hline Trial & $\mathrm{L}(\mathrm{N})$ & $\mathrm{G}(\mathrm{mesh})$ & $\mathrm{D}(\mathrm{m})$ & $\mathrm{S}\left(\mathrm{ms}^{-1}\right)$ \\
\hline 1 & 3 & 1000 & 25 & 0.04 \\
\hline 2 & 3 & 1000 & 25 & 0.04 \\
\hline 3 & 3 & 1000 & 25 & 0.04 \\
\hline 4 & 3 & 400 & 45 & 0.08 \\
\hline 5 & 3 & 400 & 45 & 0.08 \\
\hline 6 & 3 & 400 & 45 & 0.08 \\
\hline 7 & 3 & 150 & 55 & 0.14 \\
\hline 8 & 3 & 150 & 55 & 0.14 \\
\hline 9 & 3 & 150 & 55 & 0.14 \\
\hline 10 & 6 & 1000 & 45 & 0.14 \\
\hline 11 & 6 & 1000 & 45 & 0.14 \\
\hline
\end{tabular}




\begin{tabular}{|l|l|l|l|l|}
\hline 12 & 6 & 1000 & 45 & 0.14 \\
\hline 13 & 6 & 400 & 55 & 0.04 \\
\hline 14 & 6 & 400 & 55 & 0.04 \\
\hline 15 & 9 & 1000 & 55 & 0.14 \\
\hline 16 & 6 & 150 & 25 & 0.08 \\
\hline 17 & 6 & 150 & 25 & 0.08 \\
\hline 18 & 6 & 150 & 25 & 0.08 \\
\hline 19 & 9 & 1000 & 55 & 0.08 \\
\hline 20 & 9 & 1000 & 55 & 0.08 \\
\hline 21 & 9 & 1000 & 55 & 0.08 \\
\hline 22 & 9 & 400 & 25 & 0.14 \\
\hline 23 & 9 & 400 & 25 & 0.14 \\
\hline 24 & 9 & 400 & 25 & 0.14 \\
\hline 25 & 9 & 150 & 45 & 0.04 \\
\hline 26 & 9 & 150 & 45 & 0.04 \\
\hline 27 & 9 & 150 & 45 & 0.04 \\
\hline
\end{tabular}

Table 9. Signal noise ratio of reinforced PTFE composites against $\mathrm{SiC}$ particle based on Taguchi $L_{27}\left(3^{4}\right) \mathrm{OA}$.

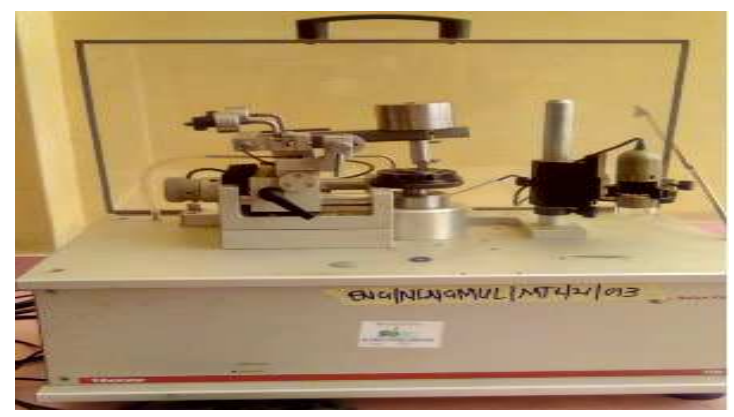

Figure 11. Arton Paar Tribometer used for the experiment.

\section{Optimization using Taguchi-Deng approach}

Taguchi optimization is capable only of optimizing a single response. However, when two or more responses of distinct features are involved Taguchi technique is limited. Thus an optimization method called Deng popularly referred to as grey relational analysis (GRA) becomes a panacea. Taguchi $\mathrm{L}_{27}\left(4^{3}\right)$ OA with Deng was used to obtain the optimum levels of tribological parameters. Data normalization is categorized as smaller or larger the better. Let the actual sequence and the comparison sequences be $X_{i}^{*}(k)$ and $\varphi_{i}(k)$, respectively. $\mathrm{i}=1,2,3 \ldots$; $\mathrm{m}=1,2,3 \ldots$ and $\mathrm{n}$ and $\mathrm{m}$ represent the total number of experiments and experimental values, respectively. Data preprocessing is used to transform the actual sequence into an identical sequence. Many data preprocessing techniques can be utilized in Taguchi-Deng method, depending upon the features of the actual sequence. Generally, series is normalized between 0 and $1^{20}$. For this study, the target value is "the smaller the better". Consequently, the actual sequence is pre-processed via equation 5.

$$
X_{i}^{*}(k)=\frac{\max \varphi_{i}(k)-\varphi_{i}(k)}{\max \varphi_{i}(k)-\min \varphi_{i}(k)}
$$

Where $X_{i}^{*}(k)=$ normalized for the ith experiment and $\varphi_{i}(k)=$ initial sequence of the average responses. After data normalization, the succeeding phase is computation of deviation sequence of the normalized data using equation (6).

$$
\Delta_{\mathrm{oi}}(\mathrm{k})=\left|\mathrm{X}_{0}^{*}(\mathrm{k})-\mathrm{X}_{\mathrm{i}}^{*}(\mathrm{k})\right|
$$

Where $\Delta_{o i}(k)=$ deviation, $X_{0}^{*}(k)=$ normalized data and $X_{i}^{*}(k)=$ comparability sequence. Grey relational coefficient (GRC) is thus estimated through equation 7.

$$
\xi_{\mathrm{i}}(\mathrm{k})=\frac{\Delta_{\min }+\zeta \Delta_{\max }}{\Delta_{\mathrm{oi}}(\mathrm{k})+\zeta \Delta_{\max }}
$$

Where $\xi_{i}(k)=$ GRC of each response, $\Delta_{\min }$ and $\Delta_{\max }=$ lowest and the highest deviations of the individual target factor, respectively. Differentiating or identification coefficient is symbolized by $\zeta$ and is demarcated within the range of $\zeta \epsilon[0,1]$. This is usually set at $1 / 2$ to assign equivalent weights to every variable. As indicated in (equation 8) GRG is then determined by taking mean of GRG of each output parameter: 


$$
\gamma_{i}=\frac{1}{n} \sum_{i=1}^{n} \xi_{i}(k)
$$

Where $\gamma_{i}=$ GRG obtained for ith test run, $\mathrm{n}=$ summation count of performance attributes. Following the determination of the optimal levels of parameter, the last phase is to predict and validate the result using equation 9:

$$
\gamma_{\text {predicted }}=\gamma_{m}+\sum_{i=1}^{q} \gamma_{0}-\gamma_{m}
$$

Where $\gamma_{0}$ represents the highest of mean GRG at optimum levels of variables and $\gamma_{m}$ defines the average GRG. $q=$ parameter that signifies factors influencing the target values.

\section{Support vector regression (SVR) model}

In 1995 Vapnik contrived and implemented support vector machine (SVM) was contrived and implemented, which is regarded an observer-based learning approach. The minimization of structural risk as well as statistical learning theory are the most important function of the SVM. Nevertheless, the properties which distinguish SVM from ANN are complexities, minimization of error as well as gain in the network's performance capability. SVM can be categorized into linear support regression as well as nonlinear support regression (NSVR). Several engineering fields such as have witnessed the application of SVM's kernel function. SVR model could be thought of as SVM on the basis of layers which include kernel function weighting on the inputs as well as function weighted sum of kernel targets. By and large, SVM is codified into two codes namely Support Vector Regression (SVR) and Support Vector Classifier (SVC) models. SVR model is made up of predictions whereas SVC model treats classifications. SVR model is designated as:

$$
f(x)=w \times \Phi(x)+b
$$

Where w stands for weight of the vector displayed in feature space, $\Phi$ shows the transfer function, $b$ is bias. Therefore, in order to show the SVR function $f(x)$, problem of regression is presented as:

Subject to the conditions:

$$
\text { Minimize: } \frac{\|w\|^{2}}{2}+C\left[\sum_{i=1}^{N} \xi+\xi^{*}\right](11)
$$

$$
\begin{aligned}
& y_{i}-f(x) \leq+\varepsilon+\xi_{i} \\
& f(x)-y_{i} \leq+\varepsilon+\xi^{*} \\
& \xi_{i}, \xi^{*}{ }_{i} \geq 0, i=1,2, \ldots N
\end{aligned}
$$

Where $\|w\|^{2}=$ weight norm vector, $\mathrm{C}=$ penalty parameter, $\xi_{i}$ and $\xi^{*}=$ slack variables. By using Lagrange functions, the solution of the nonlinear regression function can be presented based on optimization as follows:

$$
f(x)=\sum_{i=1}^{N}\left(\alpha_{i}-\alpha_{i}^{*}\right) K\left(x, x_{i}\right)+b
$$

Where $K\left(x, x_{i}\right)$ shows the kernel function and are binary variables $\left(\alpha_{i}\right.$ and $\left.\alpha_{i}^{*}>0\right)$. There exist several kinds of kernel functions including sigmoid, linear, polynomial but the commonly used kernel function is the radial basis function (RBF). Consequently, the RBF kernel was used in this study and it is expressed as (equation 13).

$$
K\left(x, x_{i}\right)=\exp \left(-\gamma\left\|x_{i}-x\right\|^{2}\right)
$$

Where $\gamma=$ kernel parameter. SVR model performance is affected by C, $\gamma$ and $\varepsilon$ (size).

\section{Harris Hawk Optimization (HHO) model}

HHO is a unique model worked out by simulating the hawk's hunting process. Lately, the procedure has been used with success in solving several intricate engineering as well as science issues. The hawks mostly operate alone whereas the Harris hawks pursue and hunt through operating and cooperating together. Hence, the HHO method is similar to Harris Hawks' natural hunting characteristic and cooperative methodology. HHO model hunting methodology entails tracing, encircling, approaching and attacking. These mechanisms are achieved in three principal phases namely: exploration, a transition from exploration to exploitation as well as exploitation (Fig. 12). 

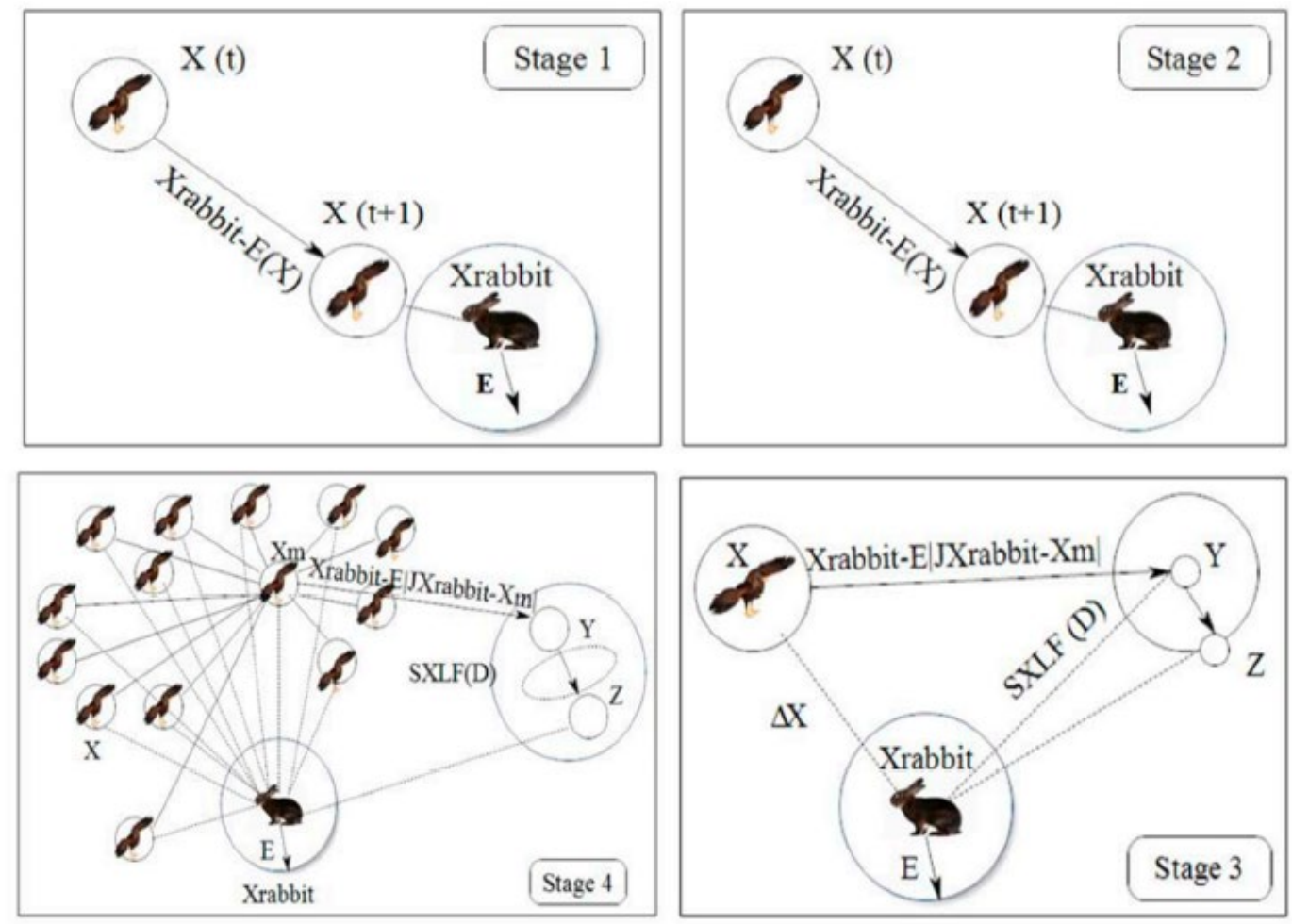

\section{Particle Swarm Optimization (PSO) model}

In 1995, PSO was presented by Kennedy and Eberhart. It is a search method based on population which is inspired by the social behaviour and dynamics of animals. The initial intention of the SPO philosophy was to clearly mimic animals' social behaviour bird flocking as an instance to detect trends that control capability of birds to fly with precision at the same time and to all of a sudden alter the direction with regathering in an optimum style. Arising from this first purpose, the philosophy inspired into a simple and efficient optimization approach. PSO is initiated with a group of random particles that look into an optimum value by updating the two best values in each iteration. The first one is named the personal best (pbest). This is the best value so far obtained by any particle in the population. All the particles explore the search space and the information collected by them is utilized for finding the best particle in the swarm referred to as global best (gbest). Thereafter, the particle updates its velocity and positions according to equations (14 and 15):

$$
\begin{gathered}
V_{i}^{k+1}=\omega V_{i}^{k}+c_{1} r_{1} \times\left(\text { pbest }_{i}^{k}-X_{i}^{k}\right)+c_{2} r_{1} \times\left(\text { gbest }^{k}-X_{i}^{k}\right) \\
X_{i}^{k+1}=X_{i}^{k}+V_{i}^{k+1}
\end{gathered}
$$

Where $V_{i}^{k+1}=$ the velocity of individual I at iteration $k+1, V_{i}^{k}=$ the velocity of individual $i$ at iteration $k, \omega$ stands for inertia weight parameter, $c_{1}$ and $c_{2}$ show the cognitive parameters, $r_{1}$ and $r_{2}=$ random numbers between 0 and $1, X_{i}^{k}=$ position of individual $\mathrm{i}$ at iteration $\mathrm{k}$, pbest $_{i}^{k}=$ the best position of individual I at iteration $\mathrm{k}$ and gbest $^{k}$ indicates the best position of the group until iteration k. Figure 13 shows the flowchart of the PSO algorithm. 


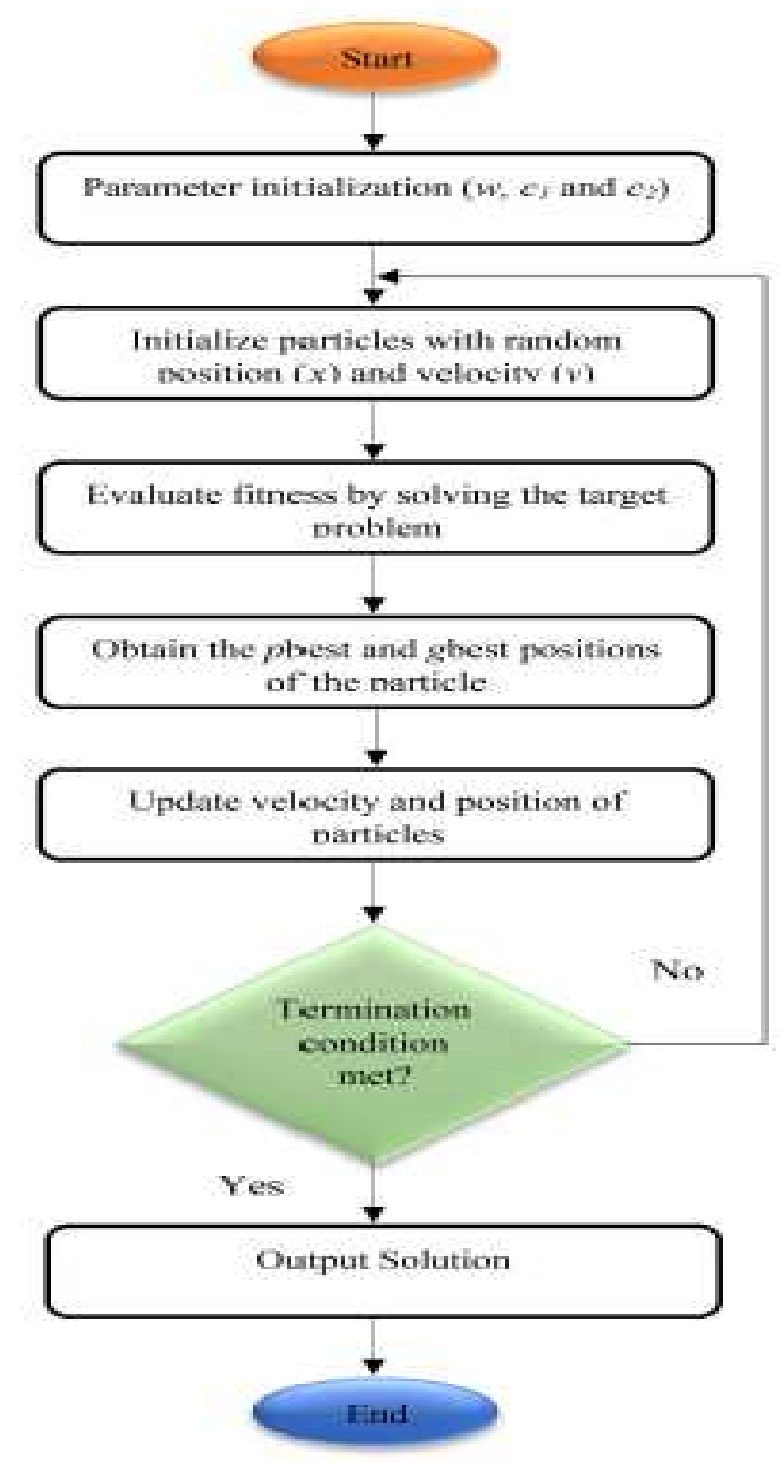

\section{Hybrid SVR model}

Improving the SVR model's performance needs a cautious delineation of parameters involved in the SVR model. The strength of the SVR model relies upon the precise choice of C, $\gamma$ and $\varepsilon$. Yet, these parameters having a wide range make the search space very large thus making it difficult to choose precise parameters. Therefore, this issue can be addressed as optimization issue that requires sorting out via optimization methods. Integration of SVR model with PSO as well as HHO models that are algorithms inspired by nature led to the following hybrid model namely: SVR-PSO and SVR-HHO for the prediction of tribological behaviours of filled PTFE composites. The nature inspired models were utilized to choose the SVR model parameters viz: $\mathrm{C}, \gamma$ and $\varepsilon$. Proposed flowchart of the hybrid model illustrated in Fig. 14. 


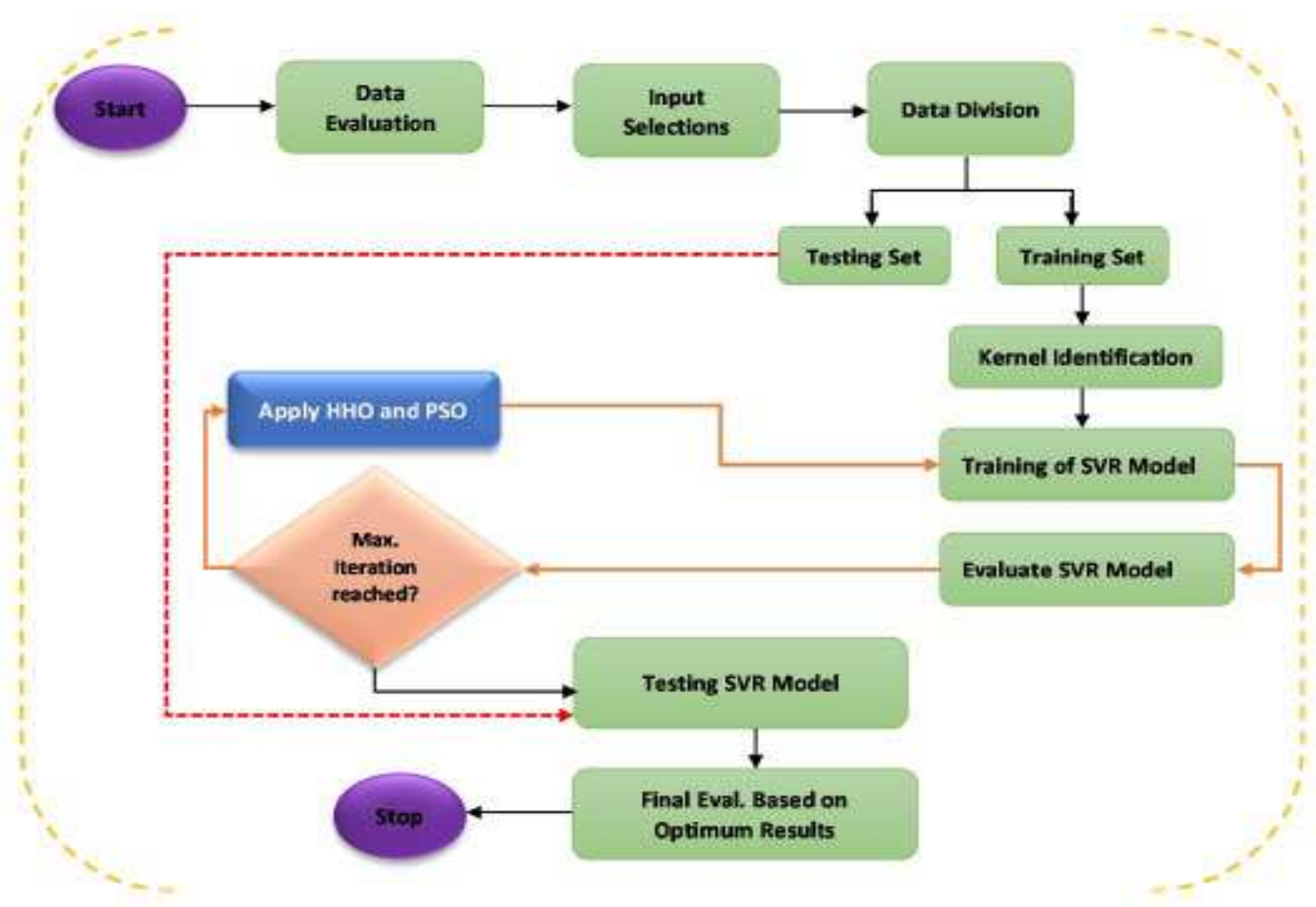

\section{Data pre-processing, model validation and performance metrics}

One of the significant aims of any soft computing model is to ascertain that models conform to acceptable data based on the models evaluation metrics utilized to obtain a dependable and strong computed outcome of the unknown data. Nevertheless, overfitting as well as local minima problems occur in the data validation. Hence, the performance of the learning phase might be unsatisfactory. This is especially when the analysis deals with a relatively small amount of dataset, as in this study. Various validation methods can be employed including crossvalidation (k-fold), hide-out and leave one out. Here, the k-fold approach was used to repeal overfitting issues. With respect to this study, the data was split into (70\%) and (30\%) for training and testing, respectively. The data obtained through abrasive experiments was pre-processed and normalized according to equation 16 . Data normalization was performed prior to model training and it usually enhances the efficiency of the predictive models. The current work introduced SVR model coupled with particle swarm optimization (PSO) and Harris Hawk optimization (HHO) models to predict abrasive tribological behaviours of filled PTFE composites. Prediction of tribological behaviours is important. However, creation of a reliable model is often challenging and difficult given the nature of the data set obtained from the experiments.

$$
y=\left(\frac{x-x_{\min }}{x_{\max }-x_{\min }}\right)
$$

Where $\mathrm{y}=$ normalized data, $x=$ is the experimental data while $x_{\max }$ and $x_{\min }$ are the maximum and minimum experimental data, respectively.

Generally, model efficiency performance should include at least one goodness of fit and at least one prediction error metrics ${ }^{50}$. Based on this determination coefficient $\left(\mathrm{R}^{2}\right)$, correlation coefficient $(\mathrm{R})$, root mean square error (RMSE) and mean absolute percentage error (MAPE) are chosen as models appraisal metrics of the soft computing methods. $\mathrm{R}^{2}, \mathrm{R}, \mathrm{RMSE}$ and MAPE are given below. These statistical tools furnish the information on efficiency of models.

$$
\begin{gathered}
R^{2}=1-\frac{\sum_{i-=1}^{N}(x-y)^{2}}{\sum_{i=1}^{N}(x-\hat{x})^{2}} \\
\mathrm{R}=\frac{\sum_{\mathrm{i}-=1}^{\mathrm{N}}(\mathrm{x}-\hat{\mathrm{x}})(\mathrm{y}-\hat{\mathrm{x}})}{\sqrt{\sum_{\mathrm{i}=1}^{\mathrm{N}}(\mathrm{x}-\hat{\mathrm{x}})^{2} \sum_{\mathrm{i}=1}^{\mathrm{N}}(\mathrm{y}-\hat{\mathrm{y}})^{2}}}
\end{gathered}
$$




$$
\begin{aligned}
R M S E & =\sqrt{\frac{\sum_{i=1}^{N}(x-y)^{2}}{N}} \\
M A P E & =\frac{1}{N}\left[\sum_{i=1}^{N}\left|\frac{x-y}{x}\right|\right]
\end{aligned}
$$

Where $x, y, \hat{x}$ and $\hat{y}$ are the actual, predicted, average actual and average predicted values, respectively.

\section{References}

1. Unal, H., Sen, U., \& A.Mimaroglu, A. Abrasive wear behaviour of polymeric materials. Mater. Des. 26(8), 705-710 (2005). https://doi.org/10.1016/j.matdes.2004.09.004.

2. Bijwe, J.; Logani, C.M.; Tewari, U. S. Influence of fillers and fibre reinforcement on abrasive wear resistance of some polymeric composites. Wear 138(1-2), 77-92 (1990). https://doi.org/10.1016/00431648(90)90169-B.

3. Khedkar, J., Negulescu, I., \& Meletis, E. I. Sliding wear behavior of PTFE composites. Wear 252(5-6), 361-369 (2002). https://doi.org/10.1016/S0043-1648(01)00859-6.

4. Suresha, B., \& Kumar, K.N.S. Investigations on mechanical and two-body abrasive wear behaviour of glass/carbon fabric reinforced vinyl ester composites. Mater. Des. 30(6), 2056-2060 (2009). https://doi.1006/j.matdes.2008.08.038.

5. Harsha, P. \& Tewari, U.S. Abrsasive wear resitance of glass fibre reinforced polysulfone composites. Indian J. Eng. Mater. Sci. 9, 203-208 (2002)

6. Kukureka, S. N., Hooke, C. J., Rao, M., Liao, P., \& Chen, Y. K. The effect of fibre reinforcement on the friction and wear of polyamide 66 under dry rolling-sliding contact. Tribol. Int. 32(2), 107-116 (1999). https:// doi.org/10.1016/S0301-679X(99)00017-1.

7. Ulas, M., Altay, O., Gurgenc, T. \& Özel, C. A new approach for prediction of the wear loss of PTA surface coatings using artificial neural network and basic, kernel-based, and weighted extreme learning machine. Friction 1-14 (2019). https:// doi.10.1007/s40544-017-0340.

8. Unal, H., Yetgin, S. H., Mimaroglu, A. \& Sumer, M. The effect of test parameters on friction and wear performance of PTFE and PTFE composites. J. Reinf. Plast. Compos. 29, 1978-1986 (2010). https:// doi.org/10.1177/0731684409340708.

9. Şahin, Y. \& Mirzayev, H. Wear characteristics of polymer-based composites. Mech. Compos. Mater. 51, 543-554 (2015). https:// doi.org/10.1007/s11029-015-9525-4

10. He, R., Chang, Q., Huang, X. \& Bo, J. Improved mechanical properties of carbon fiber reinforced PTFE composites by growing graphene oxide on carbon fiber surface. Compos. Interfaces 25, 995-1004 (2018). https:// doi.org/10.1080/09276440.2018.1451677..

11. Suh, J. \& Bae, D. Mechanical properties of polytetrafluoroethylene composites reinforced with graphene nanoplatelets by solid-state processing. Compos. Part B Eng. 95, 317-323 (2016). https:// doi.org/10.1016/j.compositesb.2016.03.082.

12. Shipway, P. H., \& Ngao, N. K. Microscale abrasive wear of polymeric materials. Wear 255(1-6) 742-750 (1-6), (2003). https://doi.org/10.1016/S0043-1648(03)00106-6.

13. Ravi Kumar B. N., Suresha B., \& V. M. Effect of particulate fillers on mechanical and abrasive wear behaviour of polyamide 66/polypropylene nanocomposites. Mater. Des. 30(9), 3852-3858 (2009). https:// doi.org/10.1016/j.matdes.2009.01.034.

14. Liu, C., Ren, L.Q., \&Tong, J. Abrsaive wear behavior of particle reinforced ultrahigh molecular weight polethylene composites. Wear 225-229, 199-204 (1999). https://doi.10.1016/S0043-1648(99)00011-3.

15. Yousif, B.F., Nirmal, U., \& Wong, K. J. Three-body abrasion on wear and frictional performance of treated betelnut fibre reinforced epoxy (T-BFRE) composite. Mater. Des. 31, 4514-4521 (2010). https://doi.org/10.1016/j.matdes.2010.04.008.

16. Pervez, M.N.; Shafiq, F.; Sarwar, Z.; Jilani, M.M.; Cai, Y. Multi-response optimization of resin finishing by using a taguchi-based grey relational analysis. Materials (Basel). 11(3), 426 (2018). https://doi.org/10.3390/ma11030426.

17. Julong, D. Introduction to Grey System Theory. J. Grey Syst. 1989, 1,. (1989).

18. Dharmalingam, S., Subramanian, R., Kok, M. Optimization of abrasive wear performance in aluminium hybrid metal matrix composites using Taguchi-grey relational analysis. J. Eng. Tribol. 227, 749-760 (2013). https:// doi.org/10.1177/1350650112467945.

19. Sylajakumari, P. A. \& Ramakrishnasamy, R. Taguchi grey relational analysis for multi-response optimization of wear in co-continuous composite. Materials (Basel). 11, 1-17 (2018). https:// 10.3390/ma11091743.

20. Saravanan K.G. \$ Rajasekaran T. Optimisation of laser parameters and dimple geometry using PCAcoupled GRG. Strojniški Vestn. - J. Mech. Eng. (2021). https://doi.org/10.5545/sv-jme.2021.7246 
21. Pervez, H.; Mozumder, M.; Mourad, A.-H. Optimization of injection molding parameters for $\mathrm{HDPE} / \mathrm{TiO}{ }_{2}$ nanocomposites fabrication with multiple performance characteristics using the Taguchi method and grey relational analysis. Materials (Basel). 9, 710 (2016). https://doi:10.3390/ma9080710.

22. Adediran, A. A., Akinwande, A. A., Balogun, O. A. \& Bello, O. S. Mechanical and optimization studies of polypropylene hybrid biocomposites. Sci. Rep. 1-17 (2022). https://doi:10.1038/s41598-022-06304-6

23. Lal, S.; Kumar, S.; Khan, Z.A.; Siddiquee, A. N. Multi-response optimization of wire electrical discharge machining process parameters for $\mathrm{Al} 7075 / \mathrm{Al}_{2} \mathrm{O}_{3} / \mathrm{SiC}$ hybrid composite using Taguchi-based grey relational analysis. Proc. IMechE Part B J. Eng. Manuf. 229, 229-237 (2015). https:/ /doi.org/10.1177/0954405414526382

24. Raykar, S.J.; Addona, D.M.D.; Mane, A. M. Multi-objective optimization of high speed turning of Al 7075 using grey relational analysis. Procedia CIRP 33, 293-298 (2015). https://doi:10.1016/j.procir.2015.06.052

25. Kuram, E.; Ozcelik, B. Multi-objective optimization using Taguchi based grey relational analysis for micro-milling of Al 7075 material with ball nose end mill. Measurement 46(6), 1849-1864 (2013). https:// doi.org/10.1016/j.measurement.2013.02.002

26. Dhande, D. Y. Comparative Analysis of Abrasive Wear Using Response Surface Method and Artificial Neural Network. J. Inst. Eng. Ser. D (2021). doi:10.1007/s40033-021-00250-9

27. Zhang, Z.; Friedrich, K. \& Velten, K. Prediction on tribological properties of short fibre composites using artificial neural networks. Wear 252, 668-675 (2002). https://doi.org/10.1016/S0043-1648(02)00023-6

28. Velten K, Reinicke R., Friedrich. K. Wear volume prediction with artificial neural networks. Tribol. Int. 33, 731-736 (2000). https://doi.org/10.1016/S0301-679X(00)00115-8

29. Jiang, Z., Zhang, Z. \& Friedrich, K. Prediction on wear properties of polymer composites with artificial neural networks. Compos. Sci. Technol. 67, 168-176 https://doi.org/10.101/jcompscitech.2006.07.026.

30. Jiang, Z., Gyurova, L., Zhang, Z., Friedrich, K. \& Schlarb, A. K. Neural network based prediction on mechanical and wear properties of short fibers reinforced polyamide composites. Mater. Des. 29, 628637 (2008). https://doi.org/10.101/j.matdes.2007.02.008.

31. Tang, J., Huang, Z., Zhu, Y. \& Zhu, J. Neural network compensation control of magnetic levitation ball position based on fuzzy inference. Sci. Rep. 1-17 (2022). https://doi:10.1038/s41598-022-05900-w

32. Haghighat Mesbahi, A., Semnani, D. \& Nouri Khorasani, S. Performance prediction of a specific wear rate in epoxy nanocomposites with various composition content of polytetrafluoroethylen (PTFE), graphite, short carbon fibers (CF) and nano- $\mathrm{TiO}_{2}$ using adaptive neuro-fuzzy inference system (ANFIS). Compos. Part B Eng. 43, 549-558 (2012). https://10.1016/j.compositesb.2011.11.026

33. Ray, S. A omparative analysis of the abrasion wear characteristics of industrial wastes filled glass / polyester composites based on the design of experiment and neural network. Polym. Compos. 1-15 (2020). https:// doi:10.1002/pc.25836

34. Dutta, S., Pal, S.K. \& Sen, R. On-machine tool prediction of flank wear from machined surface images using texture analyses and support vector regression. Precis. Eng. 43, 34-42 (2016). https://doi.org/10.1016/j.precisioneng.2015.06.007

35. Bhattacharyya, P. \& Sanadhya, S.K. Support vector regression based tool wear assessment in face milling. Proc. IEEE Int. Conf. Ind. Technol. 2468-2473 (2006). https://doi:10.1109/ICIT.2006.372659

36. Kalantary, S., Jahani, A., Pourbabaki, R. \& Beigzadeh, Z. Application of ANN modeling techniques in the prediction of the diameter of PCL/gelatin nanofibers in environmental and medical studies. RSC Adv. 9, 24858-24874 (2019). https://doi:10.1039/c9ra04927d

37. Varun, S, Sanjay, S. Om Prakash, V., Bhuvnesh, B., Tarun, K.S \& Nikhil, P. Prediction and optimization of abrasive wear loss of ultrahigh strength martensitic steel using response surface methodology, Harris Hawk and artificail neural network. Int $J$ Syst Assu Eng Manag 1-16 (2021). https://doi.org/10.1007/s13198-021-01160-5

38. Chowdhury, M. A. et al. Experimental Investigation of friction coefficient and wear rate of composite materials sliding against smooth and rough mild steel counterfaces. Tribol. Ind. 35, 286-292 (2013). https://doi.org/10.1016/j.proeng.2015.05.106

39. Gunes, I., Uygunoğlu, T. \& Çelik, A. G. Tribological properties of fly ash blended polymer composites. Matéria 26, 1-11 (2021). https://doi.org/10.1590/S1517-707620210001.1229

40. Bahadur, S., \& Sunkara, C. Effect of transfer film structure, composition and bonding on the tribological behavior of polyphenylene sulfide filled with nano particles of $\mathrm{TiO}_{2}, \mathrm{ZnO}, \mathrm{CuO}$ and $\mathrm{SiC}$. Wear 258, 14111421 (2005). https://doi.org/10.1016/j.wear.2004.08.009

41. Schwartz, C.J., \& Bahadur, S. The role of filler deformability, filler-polymer bonding, and counterface material on the tribological behavior of polyphenylene sulfide (PPS). Wear 251, 1532-1540 (2001). https://doi.org/10.1016/S0043-1648(01)00799-2

42. Basavarajappa, S., Arun, K.V., \& Davim, J.P. Effect of filler materials on dry sliding wear behavior of polymer matrix composites-A Taguchi approach. J. Miner. Mater. Charact. Eng. 8, 379-391 (2009). 
https://doi.10.4236/jmmce.2009.85034

43. Chand, N., Naik, A., \& Neogi, S. Three-body abrasive wear of short glass fibre polyester composite. Wear 242, 38-46 (2000). doi.org/10.1177/0021998307078730

44. Wojceichowski, S.; Maruda, R.W.; Krolczyk, G.M.; Nieslony, P. Application of signal noise ratio and grey relational analysis to minimze forces and vibrations during precise ball end milling. Precis. Eng. 51, 582-5596 (2018). https://doi.org/10.1016/j.precisioneng.2017.10.014

45. Yu, J.; Kim, C.-H.; Rhee, S.B. The comparison of lately proposed Harris Hawks optimization and Jaya optimization in solving directional overcurrent relays coordination problem. Complexity 1-22 (2020). https://doi.org/10.1155/2020/3807653

46. LeGates, D.R.; McCabe, G.J., J. Evaluating the use of "goodness-of-fit" Measures in hydrologic and hydroclimatic model validation. Water Resour. Res. 35, 233-241 (1999). https://doi.org/10.1029/1998WR900018

47. Moriasi, D.N.; Arnold, J.G.; Van Liew, M.W.; Bingner, R.L.; Harmel, R.D.; Veith, T. L. Model evaluation guidelines for systematic quantification of accuracy in watershed simulations. Trans. ASABE 50, 885-900 (2007). https://doi:10.13031/2013.23153

48. Musa, B., Yimen, N., Abba, S. I. \& Adun, H. H. Multi-state load demand forecasting using hybridized support vector regression integrated with optimal design of off-grid energy systems - A metaheuristic approach. Proceses 1166 (2021). https:// doi.org/10.3390/pr9071166

49. Islam, M.Z.; Wahab, N.I.A.; Veerasamy, V.; Hizam, H.; Mailah, N.F.; Guerrero, J.M.; Nasir, M. N. M. A Harris Hawks optimization based single- and multi-objective optimal power flow considering environmental emission. Sustainability 12, 5248. (2020). https://doi.org/10.3390/su12135248

50. S.I. Abba, M.S.Gaya, M.L. Yakubu, M.U. Zango, R.A. Abdulkadir, A.I. Tukur, \& N. A. W. Modelling of Uncertain System : A comparison study of Linear and Non-Linear Approaches. 1-6 (2020). https://doi. 10.1109/I2CACIS.2019.8825085

\section{Author contributions statement}

M.A.I. designed, conducted and analyzed the experiments and the results. S.IA. performed the simulation. H.C and M.A.S reviewed the manuscript.

\section{Additional information}

All correspondences should be addressed to M.A.I. 